\title{
p53 in recombination and repair
}

\author{
SA Gatz ${ }^{1}$ and L Wiesmüller ${ }^{\star 2}$ \\ ${ }^{1}$ Universitätsklinik für Kinder- und Jugendmedizin, Eythstr. 24, 89075 Ulm, \\ Germany \\ 2 Universitätsfrauenklinik, Prittwitzstr. 43, 89075 Ulm, Germany \\ * Corresponding author: L Wiesmüller, Gynaecological Oncology, Universitäts- \\ frauenklinik, Prittwitzstr. 43, 89075 Ulm, Germany. Tel: + 49-731-500-27640; \\ Fax: + 49-731-500-26674; \\ E-mail: lisa.wiesmueller@uni-ulm.de
}

Received 16.12.05; revised 20.2.06; accepted 22.2.06; published online 17.3.06 Edited by G Melino

\begin{abstract}
Convergent studies demonstrated that p53 regulates homologous recombination (HR) independently of its classic tumour-suppressor functions in transcriptionally transactivating cellular target genes that are implicated in growth control and apoptosis. In this review, we summarise the analyses of the involvement of p53 in spontaneous and double-strand break (DSB)-triggered HR and in alternative DSB repair routes. Molecular characterisation indicated that p53 controls the fidelity of Rad51-dependent HR and represses aberrant processing of replication forks after stalling at unrepaired DNA lesions. These findings established a genome stabilising role of $p 53$ in counteracting errorprone DSB repair. However, recent work has also unveiled a stimulatory role for p53 in topoisomerase l-induced recombinative repair events that may have implications for a gain-offunction phenotype of cancer-related p53 mutants. Additional evidence will be discussed which suggests that p53 and/or p53-regulated gene products also contribute to nucleotide excision, base excision, and mismatch repair.

Cell Death and Differentiation (2006) 13, 1003-1016.

doi:10.1038/sj.cdd.4401903; published online 17 March 2006
\end{abstract}

Keywords: excision repair; homologous recombination; mismatch repair; nonhomologous end-joining; topoisomerase I

Abbreviations: 53Bp1, p53 binding protein 1; AP site, apurinic/ apyrimidinic site; Ape, AP endonuclease; Atm, ataxia telangiectasia mutated protein; Atr, Atm- and Rad3-related protein; BER, base excision repair; Blm, Bloom's syndrome protein; Brca1 protein, breast cancer-related 1protein; Brca2, breast cancerrelated 2 protein; CS, Cockayne syndrome; DNA-PK, DNAdependent protein kinase; DSB, double-strand break; Fanc, Fanconi anemia complementation group; Hdm2, human equivalent of mouse double minute 2; HPV, human papilloma virus; HR, homologous recombination; IR, ionising radiation; Karp-1, Ku86 Autoantigen-related protein-1; LOH, loss of heterozygosity; Mdm2, mouse double minute 2; Mlh1, MutL homologue; MMR, mismatch repair; MRN, complex comprising Mre11, Rad50, and
Nbs1; Msh2/3/6, MutS homologue 2/3/6; NER, nucleotide excision repair; NHEJ, nonhomologous end-joining; NO, nitric oxide; p53pSer15, p53 phosphorylated on serine 15; PCNA, proliferating cell nuclear antigen; PIKK, phosphatidylinositol 3kinase-related kinases; Pms2, postmeiotic segregation 2; Parp-1, poly(ADP-ribose) polymerase 1; Ref-1, redox factor 1; RPA, replication protein $A$; SSA, single-strand annealing; $\mathrm{TfIIH}$, transcription factor $\mathrm{IIH}$; TK, thymidine kinase; Wrn, Werner syndrome protein; $\mathrm{XP}$, xeroderma pigmentosum; xeroderma pigmentosum group $\mathrm{B} / \mathrm{C} / \mathrm{D} / \mathrm{E} / \mathrm{G}$ protein, $\mathrm{XPB} / \mathrm{XPC} / \mathrm{XPD} / \mathrm{XPE} /$ $X P G$

\section{Introduction}

Soon after having established TP53 as the most frequently altered gene in human tumours in the 1990s, ${ }^{1,2}$ p53 was understood as a major component of the DNA damage response pathway. ${ }^{3,4}$ After the introduction of DNA injuries the level of p53 protein rises, which in turn induces a transient cell cycle arrest or apoptotic cell death. DNA damage activates p53 through post-translational modifications by specific kinases, such as the strand break sensor ataxia telangiectasia mutated protein (Atm), by acetyltransferases like CREB-binding protein (Cbp)/p300, and by the poly(ADPribose) polymerase 1 (Parp-1), which prevent proteolysis via the Arf-mouse double minute 2 (Mdm2) pathway and/or enhance binding of p53 to consensus sequences within the genome. ${ }^{5-7}$

Work on cells from mice nullizygous for TRP53 and on tumour cells differing in the TP53 status revealed that p53 not only responds to DNA damage, but in fact represents a central player in genome stabilisation, thereby counteracting the multistep process of tumorigenesis. Impaired p53 function was shown to be associated with its inability to prevent genetic instabilities, which become manifested as aneuploidies, allelic losses, as well as increases in sister chromatid exchanges and in gene amplification rates. ${ }^{8-11}$ Moreover, already in 1995, Reddel and co-workers ${ }^{12}$ noticed that loss of wild-type TP53 during spontaneous immortalisation of Li-Fraumeni fibroblasts is associated with telomere elongation through a telomerase-independent, alternative pathway and proposed a mechanism involving recombination.

Initially, investigations on a direct participation of p53 in DNA repair were spurred by a number of biochemical observations. Thus, the C-terminal 30 amino acids of p53 were shown to recognise several DNA damage-related structures, such as DNA ends, gaps, and insertion/deletion mismatches. ${ }^{13-16}$ p53 was also demonstrated to catalyse reannealing of short stretches of single- and double-stranded DNA and to promote strand exchange between them. ${ }^{13,17-19}$ Further, p53 binds to three-stranded heteroduplex joints and four-stranded Holliday junction DNA structures with localisation specifically at the junction, suggesting that p53 directly participates in recombinational repair. ${ }^{20-22}$ Moreover, several 


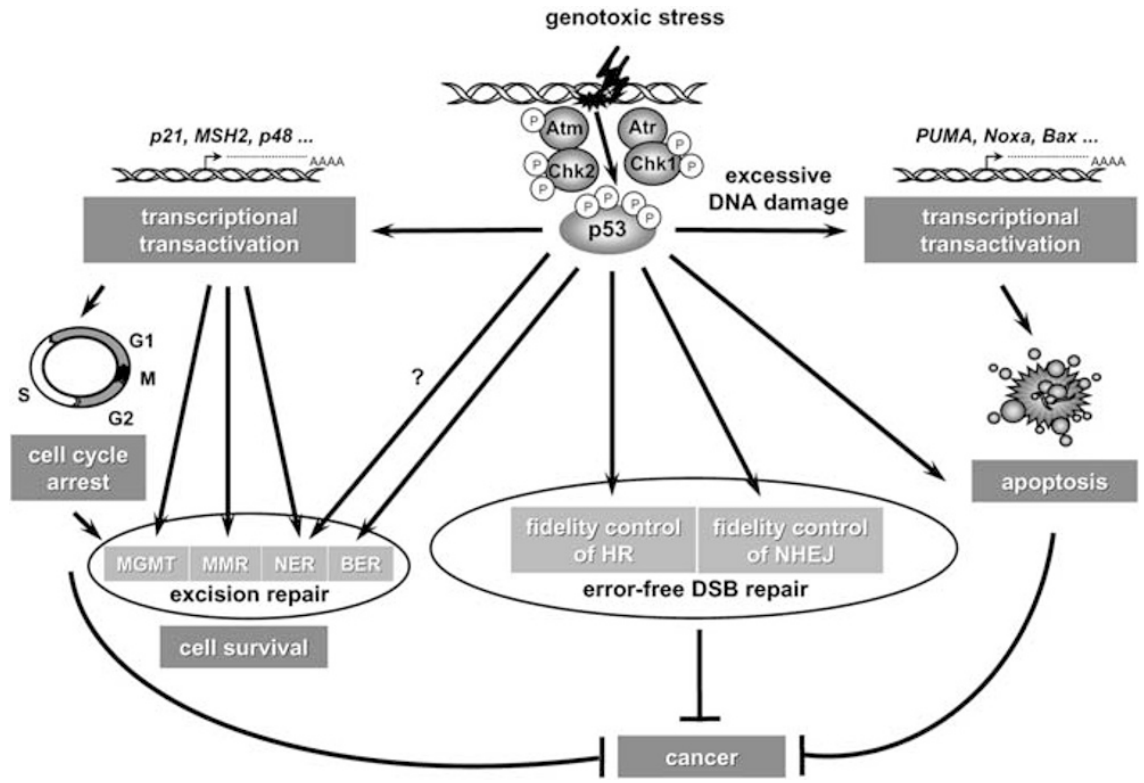

Figure 1 p53 exhibits multiple activities in DNA repair and checkpoint control. In response to genotoxic stress, damage sensing kinases like Atm and Atr phosphorylate p53 at multiple sites, thereby modulating its downstream activities. ${ }^{174}$ p53 activates target genes like CDKN1A, Msh2, and p48 to give time for repair and to directly promote removal of alkyl adducts (MGMT), mismatch repair (MMR), and nucleotide excision repair (NER), respectively. In cells exceeding a critical threshold of DNA damage, transcriptional transactivation of proapoptotic genes such as PUMA, NOXA, and BAX induces the active cell death programme. There is growing evidence for a direct role of p53 in the fidelity control of HR and NHEJ to ensure error-free DSB repair and, therefore, to suppress detrimental genome rearrangements that drive cancer. Moreover, direct physical interactions of p53 with components of the BER and NER machinery may underlay enhancement of BER and possibly also of NER ${ }^{31,32,33}$

groups demonstrated a $\mathrm{Mg}^{2+}$-dependent $3^{\prime}-5^{\prime}$ exonuclease activity intrinsic to p53. ${ }^{19,23-29}$ Noticeably, the same central region within $\mathrm{p53}$, where tumourigenic mutations are clustered, recognises DNA sequence specifically, is required for junction-specific binding of heteroduplex joints and is necessary and sufficient for the $3^{\prime}-5^{\prime}$ exonuclease activity on DNA. ${ }^{23,25,30}$ In addition to p53's biochemical activities, numerous reports on physical and functional protein interactions further strengthened the proposal of a direct role of p53 in nucleotide excision repair (NER), base excision repair (BER), and double-strand break (DSB) repair (see Figure 1). ${ }^{31-33}$

\section{p53 Transcriptionally Regulates Several DNA Repair-related Genes}

Until the burst of DNA repair-related studies in recent years, genome stabilising functions of p53 were explained by its ability to signal cell cycle arrest at the G1/S and G2/M transition, thereby giving time for DNA repair before the entry into S phase, and by inhibition of mitotic division in damaged cells. p53 activates transcription of more than 100 genes through binding to particular DNA sequences, with p53's cell cycle control functions mainly relying on the cyclin-dependent kinase regulatory products of two genes, CDKN1A and 14-3$3 \sigma$. To avoid the manifestation of DNA damage in response to excessive or irreparable damage, p53 induces apoptotic cell death. Apoptotic signalling involves activation of target genes like PUMA, NOXA, and BAX and, as discovered most recently, direct protein interactions with members of the $\mathrm{Bcl}$ -
2 protein family to promote mitochondrial outer membrane permeabilisation. ${ }^{3,4,34-37}$

Although several observations suggest a direct involvement of p53 in NER (see below), there is growing evidence for a transcription-dependent role of p53 in NER (see Figure 1). NER removes a variety of DNA lesions, including photoproducts induced by UV and other bulky lesions, and can be subdivided into the global genomic repair (GGR) and the transcription-coupled repair (TCR) pathway depending on the mode of damage recognition in the entire genome versus actively transcribed regions. In GGR, the heterodimeric complex of XPC-hHR23B appears to be the first NER factor to bind the lesion. $\mathrm{p} 48^{\mathrm{DDB} 2}$ which is encoded by the $D D B 2$ gene mutated in patients belonging to the XP complementation group $\mathrm{E}$, is thought to stimulate XPC-mediated recognition of cyclobutane pyrimidine dimers (CPDs) during GGR together with its heterodimer partner $\mathrm{p} 125^{\mathrm{DDB} 1}$.38,39 Two groups noticed decreased GGR but not TCR efficiencies after loss of p53 function in Li-Fraumeni patient fibroblasts carrying TP53 mutations or in human papilloma virus (HPV)-E6 expressing mammary epithelial cells. ${ }^{40,41}$ Later on, transcriptional transactivation of the $X P C$ gene and the human, but not the murine, $D D B 2$ gene by p53 were discovered, thereby unveiling the molecular links between p53 and GGR and providing further insight into the differences in DNA repair between humans and mice. ${ }^{42-45}$ With respect to a potential role of p53 in TCR controversial data have been reported. However, for TCR assessment, experiments that measure the recovery of transcription from UV-damaged reporter genes were frequently applied, so that one possible explanation for apparent discrepancies could be a defect in a post-repair 
process required for mRNA synthesis recovery rather than in TCR itself. ${ }^{46}$

Another p53-regulated gene, GADD45, was originally proposed to also participate in GGR downstream of p53. ${ }^{47}$ However, according to more recent reports alternative functions of GADD45 in remodelling chromatin to give access to the sites of DNA damage are more likely. ${ }^{48}$ The identification of the p53R2 p53 target gene encoding a ribonucleotide reductase caused much excitement, because work from yeast and mouse had suggested an important role for this enzyme in supplying precursors for DNA repair. Consistently, p53dependent upregulation was seen to follow DNA damage and to cause increased $\left[{ }^{3} \mathrm{H}\right] \mathrm{dCTP}$ incorporation into the damaged genome. ${ }^{49}$ In view of the discriminatory role of p53 in GGR versus TCR, it will be insightful to precisely define the influence of p53R2 on distinct repair pathways to better understand the biological meaning of this finding. Interestingly, the tumour-suppressor breast cancer-related 1 protein (Brca1protein) has been demonstrated to increase expression of the p53 target genes CDKN1A, 14-3-3 $\sigma, X P C, D D B 2$, $G A D D 45$, and $p 53 R 2^{50,51}$ Indeed, an early hypothesis on the possible function of Brca1 was to play an auxiliary role in p53-dependent transcriptional transactivation. ${ }^{52}$ However, later studies demonstrated additional, p53-independent functions of Brca1 in GADD45 activation, in controlling the checkpoint during the G2/M phase, and in inducing apoptosis. ${ }^{53}$ Therefore, today Brca1 is considered to regulate DNA repair and DNA damage signalling via p53-dependent and independent pathways.

Alkyl adducts at the $\mathrm{O}^{6}$ position of guanine can be directly repaired by $\mathrm{O}^{6}$-methyl-guanine-DNA-methyl-transferase (MGMT). Damage-induced expression of the enzyme depends on p53 in murine fibroblast cell lines and animals. ${ }^{54,55}$ BER is the main pathway responsible for the repair of damage resulting from deamination, oxidation, and alkylation of DNA bases and is generally thought to reverse damage produced by IR. The first step in the BER pathway is executed by glycosylases, which hydrolyse the $N$-glycosylic bond between the deoxyribose sugar moiety and the DNA base. ${ }^{56}$ Rotter and co-workers showed that p53 promotes activation of 3-methyl adenine DNA glycosylase (3-MeAde DNA glycosylase) in response to $\gamma$-ray treatment. Surprisingly, this initial step in $\mathrm{BER}$ is also subject to negative transcriptional regulation by p53. Thus, following exposure to nitric oxide (NO) p53 downregulates 3-MeAde DNA glycosylase via transcriptional trans-repression. ${ }^{57}$ Recently, Donehower and co-workers identified PPM1D as a p53-induced gene following UV and ionising radiation (IR). ${ }^{58}$ PPM1D phosphatase interacts with Uracil DNA glycosylase (Ung) 2 and suppresses BER probably via dephosphorylation of Ung2. In analogy to the Mdm2 feedback loop, these negative regulatory mechanisms executed by p53 may serve to return DNA repair to the deactivated state.

The identification of MutS homologue $2(M S H) 2, M L H 1$, and postmeiotic segregation 2 (PMS2) as p53 target genes has linked p53 to mismatch repair (MMR). ${ }^{59-61}$ MMR is in charge of DNA repair following DNA polymerase errors, removes mismatches in heteroduplex DNA during recombination, and prevents recombination between similar, but nonidentical (homeologous) sequences. ${ }^{62,63}$ Defects in MMR can lead to a mutator phenotype, which is predisposing to different types of cancer, both familial and sporadic. Inherited defects in genes of the MMR system are implicated in the aetiology of Hereditary Non-Polyposis Colorectal Cancer (HNPCC). ${ }^{64}$ Msh2 in complex with Msh6 or Msh3 is active in the recognition of single base mismatches and short insertion/ deletion mispairs or larger loops of unpaired nucleotides, respectively. The central MutL homologue (MIh1), which can form heterodimeric complexes with three other MutL homologues Pms2, Pms1, and Mlh3. Mlh1-Pms2 is the major human MutL heterodimer, whereas Mlh1-Pms1 and Mlh1Mlh3 play only minor roles in MMR and are suspected to be redundant with respect to Mlh1-Pms2. The aforementioned studies, therefore, suggest that p53 increases the fidelity of DNA replication and homologous recombination $(\mathrm{HR})$ by transcriptional transactivation of MMR genes. Additionally, the p53 target genes $M S H 2, M L H 1$, and PMS2 are able to signal cell cycle arrest and apoptosis after certain types of DNA damage via p53 or its homologue p73. ${ }^{65}$

So far, only very few reports described a possible regulatory role of p53 in the transcription of genes related to DSB repair, whereas growing evidence indicates a direct role of p53 in this repair pathway (see below). Gel shift experiments showed that wild-type $\mathrm{p53}$ binds to a p53 consensus sequence in the promoter of the gene coding for the Fanconi anemia complementation group C (Fanc C) protein. Consistently, p53-dependent activation of the endogenous FANC $C$ gene was also observed. ${ }^{66}$ Surprisingly, however, tumour-derived mutants $\mathrm{p} 53(175 \mathrm{H})$ and $\mathrm{p} 53(273 \mathrm{H})$ retained FANC $C$ gene activation. Further, results from transient luciferase reporter assays did not support a stimulatory role of p53 in FANC C transcription, so that it remains open how p53 may affect FANC C gene expression. A p53 binding site was also found in the KARP-1 gene locus. ${ }^{67}$ Ku86 Autoantigen-related protein-1 (Karp-1) is thought to play a role in DSB repair as a regulator of DNA-dependent protein kinase (DNA-PK). However, because DNA damage-induced KARP-1 gene upregulation was compared using TP53-positive and -negative cell lines of different origins, the proposed dependency on p53 awaits further confirmation.

Taken together, p53 has an influence on a set of DNA repair, cell cycle regulatory, and proapoptotic genes via transcriptional regulation. Thus, p53 participates in the different branches of the cellular decision making process in choosing between the removal of repairable damage to promote cell survival and the elimination of cells with excessive and irrepairable DNA damage to protect the organism from genetically unstable cells that drive cancer.

\section{Does p53 have a Direct Role in NER and BER?}

Following damage recognition by XPC-hHR23B in GGR and stalled RNA polymerase II together with Cockayne syndrome (CS) proteins in TCR, the initial complexes attract transcription factor $\mathrm{IIH}(\mathrm{Tfl} I \mathrm{H})$, which consists of the xeroderma pigmentosum group $B$ protein (XPB) and XPD and the general transcription factors p62, p52, p44, and p34. XPB and XPD exhibit helicase activity of opposite polarity and partially 
unwind the DNA around the damaged site. TfIIH, then, recruits the nuclease XPG, XPA to confirm the presence of the lesion, and the human ssDNA binding protein, replication protein $A$ (RPA), to stabilise the bubble structure. Subsequently, Ercc1XPF is recruited and XPG and Ercc1-XPF excise an oligonucleotide of 24-32 nucleotides containing the lesion, which is filled in by the regular DNA replication machinery. ${ }^{38,39}$

Already in 1995, three groups reported on defective NER in cells with reduced levels of wild-type p53. ${ }^{40,68,69}$ Wang et al. ${ }^{69}$ additionally described physical interactions between the Cterminal end of p53 and the TfIIH subunits XPB and XPD as well as the TCR factor CSB, suggesting that $p 53$ regulates NER through these helicase activities. Wild type, but not mutant p53, was found to inhibit XPB and XPD activities, which was hypothesised to stimulate a stable helicasedamaged DNA complex. Although strong physical contacts between p53 and the TfIIH complex and inhibition of helicase activities could be confirmed, Leveillard et al. ${ }^{70}$ like other groups were unable to demonstrate an effect of p53 on NER with naked DNA in vitro. However, excision repair is strongly affected by chromatin structure, and several histone modifying and ATP-dependent remodelling enzymes are engaged in the regulation of the accessibility of DNA in chromatin. Rubbi and Milner ${ }^{71}$ recently discovered a new role of p53 in regulating chromatin relaxation during GGR. However, studies indicating that the requirement for p53 in NER can be bypassed by overexpression of damage recognition factors argue against a direct participation of $\mathrm{p} 53,{ }^{51}$ so that uncertainties remain on the implications of $\mathrm{TfllH}$ and chromatin interactions for the role of p53 in NER.

After the initial BER step executed by glycosylases, which generates an apurinic/apyrimidinic (AP) site, AP endonuclease (Ape/Ref-1, redox factor 1 ) is required to hydrolyse the DNA sugar-phosphate backbone $5^{\prime}$ of the apurinic/apyrimidinic site (AP site). On the major BER route, the short patch pathway, Ape then recruits polymerase $\beta$. Polymerase $\beta$ fills in the missing, single nucleotide and, in the case of initial cleavage by monofunctional glycosylases, excises the $5^{\prime}$ terminal deoxyribosephosphate residue by its lyase domain. Finally, Ligase 3 interacts with polymerase $\beta$ via Xrcc1 and the Ligase 3 -Xrcc1 heterodimer seals the nick. ${ }^{56}$ Besides serving as a nuclease and an assembly factor in BER, APE additionally activates transcription factors such as AP-1 and p53, through regulation of the redox state. Since 1999, Rotter's group has provided accumulating evidence suggesting a direct involvement of p53 in BER. ${ }^{72-74}$ In these studies, an augmented BER activity was observed when cell extracts with overexpressed p53 were applied to in vitro BER assays. Later on, p53 was shown to interact with polymerase $\beta$ indicating a direct role of p53 in BER. ${ }^{75}$ Moreover, Ape/Ref-1 also binds to $\mathrm{p} 53$, contributes to redox-dependent $\mathrm{p} 53$ protein stabilisation, and enhances both DNA binding and p53 transactivation. ${ }^{76-78}$ Zhou et al. ${ }^{75}$ investigated the molecular mechanism underlying p53-dependent BER stimulation in more detail. From their data the authors concluded that direct physical interactions between the $\mathrm{N}$-terminal 96 amino acids of p53 and polymerase $\beta$ cause enhanced, Ape/Ref-1 facilitated loading of polymerase $\beta$ on abasic DNA and stabilised complex formation. Unfortunately, contradictory observations have been made with p53 mutated at amino acids 22 and 23 or at the $\mathrm{C}$-terminus, so that it remains open in how far p53 activities exerted by the $\mathrm{N}$ - and C-terminal domains influence BER. ${ }^{73,75}$ Importantly, cancer-related p53 core domain mutants were unanimously reported to exhibit strongly reduced stimulatory activities in BER. ${ }^{73,75}$ Further support for the concept of a direct involvement of p53 in BER has come from a study by Seo et al. ${ }^{79}$ demonstrating that the cells from TRP53 mutant or null mice performed modestly reduced BER of methyl methanesulfonate (MMS) damage, showed MMS sensitivity, and reduced levels of polymerase $\beta$, possibly due to stabilising interactions between p53 and the polymerase particularly within p53-DNA complexes at damaged sites. However, data from a study by Sobol et al. ${ }^{80}$ questioned that p53 is an essential component of this repair pathway. Still, first indications for an involvement of p53 in mitochondrial BER were also found, thereby initiating new ideas on the potential role of mitochondrial p53. In mitochondria p53 appears to stimulate polymerase $\gamma$-mediated repair synthesis. $^{81}$

Harris and co-workers ${ }^{82}$ made the interesting observation that damage-induced apoptosis is delayed in XPD lymphoblastoid cells and depends on p53. As blockage of the transcription machinery causes p53-dependent apoptosis, it is conceivable that functional p53-TfIIH interactions, possibly also involving phosphorylation of p53 by the cyclin $\mathrm{H}-\mathrm{Cdk} 7$ component of $\mathrm{TfllH}$, modulate apoptosis induction depending on the extent of elongation-blocking DNA lesions. ${ }^{83}$ Finally, Rotter and co-workers ${ }^{74}$ noticed that depending on the severity of DNA damage p53 promotes BER or apoptosis, suggesting the existence of a p53-dependent switch mechanism between DNA repair and apoptosis also with respect to BER. In line with this idea, interactions between p53 and the NER component RPA were found to inhibit sequence-specific DNA binding, to become disrupted in the presence of ssDNA and after UV damage, and to be inversely related to the cellular GGR capacity. ${ }^{84,85}$

\section{Impaired p53 Function Associates with a Mutator Phenotype, which is Related to Aberrant DSB Repair in vitro and in vivo}

DSBs are caused spontaneously during physiological DNA processing in replication, Ig and TCR gene diversification, and meiosis and can arise from exogenous sources, including IR or cancer chemotherapeutic agents. DSBs are the most severe type of DNA damage, and efficient removal of DSBs is taken care of by two principal repair pathways: nonhomologous end-joining (NHEJ) and homology-based repair. ${ }^{86,87}$ In the NHEJ pathway, Ku70 and Ku80 bind the DSB, followed by recruitment and activation of the catalytic subunit of the DNA protein kinase (DNA-PK $\mathrm{C}_{\mathrm{cs}}$ ), which mediates synapsis, recruits the ligating compounds Xrcc4 and DNA Ligase 4, and activates the putative end-processing nuclease Artemis. ${ }^{88}$

Pathways that utilise sequence homology for repair are subdivided into two types, based on whether homologous associations arise from strand annealing activities (singlestrand annealing, SSA) or from strand exchange (HR) activities. $^{86,87}$ In mammalian cells one of the first, if not the initial step, in both pathways is the recognition of DSBs by a 
protein complex comprising Mre11, Rad50, and Nbs1 (MRN). The MRN complex is involved in virtually all aspects of DNA end metabolism, including DSB detection, tethering of the two DNA substrates, DSB processing, and checkpoint signalling via activation of the phosphatidylinositol 3-kinase-related kinases (PIKK), Atm, and Atr (Atm- and Rad3-related protein). ${ }^{89-91}$ Following DNA end resection to yield 3'-ssDNA tails, HR involves strand exchange reactions with an intact homologous duplex catalysed by the human RecA counterpart, Rad51. Rad52 promotes formation of the Rad51 nucleoprotein filament, the Snf2/Swi2 helicase Rad54 accelerates homology search by Rad51. ${ }^{92}$ SSA does not rely on Rad51 but requires Rad52. Rad52 facilitates pairing of the processed ssDNA tails before removal of the heterologous overhangs by the structure-specific endonuclease Ercc1XPF. Emphasising the importance of Rad52 for the SSA pathway, $R A D 52^{-1-}$ mouse cells do not show an HR defect, but SSA is decreased. ${ }^{86,93}$

NHEJ underlies $V(D) J$ recombination and reseals DSBs in mitotically growing cells during the whole cell cycle. HR mediates genetic mixing during meiosis. In mitotically growing cells, HR is confined to the $S$ and $G 2$ cell cycle phases, when homologous sister chromatids are available. ${ }^{94}$ NHEJ is frequently associated with the gain or loss of nucleotides at the break site, SSA occurs between repeated sequences and ultimately creates a deletion, and, therefore, is always mutagenic. HR is considered the most error-free pathway, because sister chromatids are the preferred template. Taken together, depending on the type and quality of the DSB repair pathway involved, the repair process may end up with deletions, loss of heterozygosity ( $\mathrm{LOH}$ ), and chromosomal translocations which may accelerate the multistep process of tumorigenesis.

Chromosome painting and microsatellite marker mapping unveiled a higher frequency of translocations and indicated deregulated NHEJ in human lymphoblastoid cells, where TP53 was inactivated (thymidine kinase (TK)6-E6) or point mutated (WTK1) as compared to the isogenic counterpart with wild-type TP53 (TK6). ${ }^{95}$ Xia et al. ${ }^{96}$ managed to distinguish between $\mathrm{LOH}$ due to NHEJ and mitotic recombination by use of a fluorescence in situ hybridisation technique, thereby confirming that a large fraction of the $\mathrm{LOH}$ mutants arose by more frequent HR events. Further investigations comparing wild-type and mutant TP53 cells revealed a higher frequency of TK gene alterations, which in part could be attributed to $\mathrm{HR}^{95}$ Therefore, both forms of DSB repair seem to operate in mutant TP53 cells to a greater extent and contribute to elevated $\mathrm{LOH}$ frequencies. Further indications for mitotic recombination events leading to $\mathrm{LOH}$ upon loss of or reduced p53 function came from investigations regarding the adenine phosphoribosyl transferase and hypoxanthine-guanine phosphoribosyltransferease loci in TRP53 ${ }^{-1-}$ mice as well as the second TRP53 allele in TRP53 ${ }^{+/-}$mice. ${ }^{97,98}$ Moreover, in the $p^{\text {un }}$ mouse model, TRP53 ${ }^{-1-}$ mice showed an elevated rate of intrachromosomal homology-based deletion events. ${ }^{99}$ Different from the observations made for gross structural changes at the chromosomal level, evidence for a mutator phenotype was not found for point mutations when using $L A C /$ reporter mice (Big Blue ${ }^{\mathcal{C}}$ ) concomitantly differing in the TRP53 status. $^{95}$
From the observation that p53 mRNA expression in testes of mice is high and specific for spermatocytes in zygotene to pachytene, it was also proposed that p53 might be involved in HR in meiotic germ cells. ${ }^{100}$ However, Gersten and Kemp ${ }^{101}$ did not observe elevated rates for meiotic HR in TRP53 knockout mice. These observations suggested that p53 specifically contributes to the suppression of aberrant DSB repair processes in mitotically growing cells.

\section{Evidence for a Direct Role of p53 in HR}

Two main methods have been established to measure HR with respect to p53. The viral, SV40-based test system measures intermolecular HR between two defective SV40 minichromosomes with $\mathrm{HR}$ reconstituting a functional viral genome within doubly infected monkey kidney cells. ${ }^{102}$ The second and more widely used assay monitors reporter gene reconstitution through inter- and intramolecular HR between tandem repeat sequences. ${ }^{103}$ The recent use of reporter gene products emitting fluorescent light rather than conferring antibiotic resistance provided a rapid readout and, therefore, allowed to distinguish between growth and death regulatory versus repair-related activities of p53. ${ }^{104,105}$ Inclusion of the rare-cutting I-Sce I endonuclease enabled Akyüz et al. ${ }^{104}$ to specifically cleave the reporter gene and, thereby, to exclude indirect effects on DSB repair due to p53-dependent activities in excision repair pathways.

Applying these tools, numerous groups observed that wild-type p53 represses HR on both extrachromosomal and intrachromosomal DNA substrates by at least one to two orders of magnitude. Vice versa, inactivation of wild-type p53 by mutation or complex formation by viral proteins increased HR by several orders of magnitude. ${ }^{21,30,102,104-110}$ In apparent contrast, Willers et al. ${ }^{111}$ reported HR not to be suppressed by wild-type p53, when employing a plasmid shuttle assay with episomally replicating substrates. However, subsequent findings, suggesting that the extent of recombination regulation by $p 53$ is influenced by the p53/DNA substrate ratio, offered low p53 expression levels relative to transfected plasmid copy numbers as a likely explanation for this conflicting result. ${ }^{104,105}$ Experiments with p53 mutants revealed severe HR inhibitory defects for all tested hotspot mutants, as was seen most convincingly when excluding dominant-negative effects between endogenous and exogenous p53 variants in a TP53-negative background. ${ }^{30,104,108}$ Importantly, amino-acid exchanges 135V (murine p53), 138V, $143 A$, and $22 Q, 23 S$, which are known to reduce or even abolish p53's transcriptional transactivation and cell cycle regulatory capacity, did not significantly affect $\mathrm{HR}$ inhibition. ${ }^{104,105,109,110,112}$ These findings demonstrated that p53 activities in transcriptional transactivation and checkpoint control are separable from its functions in homology-based DSB repair and provided convincing evidence for a direct role of p53 in HR (see Figure 2).

The formation of DSBs has recently been discovered to represent a frequent byproduct of normal DNA replication, and these DSBs generated at the replication fork are repaired by both NHEJ and HR. ${ }^{113}$ Moreover, replication blocking lesions such as bulky adducts are subject to HR repair, 


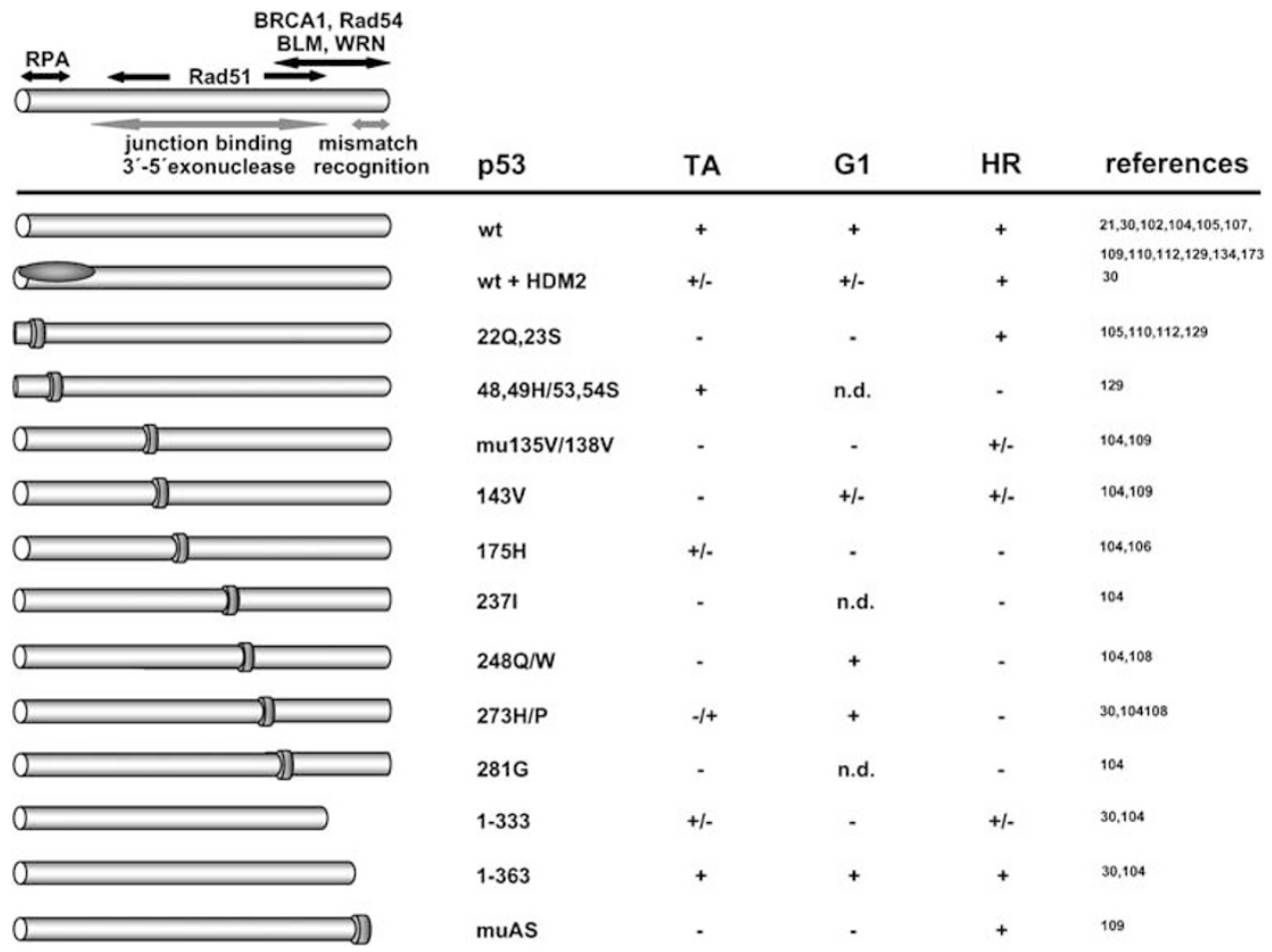

Figure 2 Separation of inhibitory functions in HR from transcriptional transactivation and cell cycle control. Accumulating evidence indicates a role of p53 in repressing HR independently of its transcriptional activation (TA) and G1 cell cycle arrest (G1) functions. In these studies p53-dependent activities in TA, cell cycle control and HR were monitored in the presence of wild-type (wt) or mutated TP53 or after expression of the human Mdm2 homologue human equivalent of mouse double minute 2 ( $\mathrm{Hdm} 2)$, which antagonises p53 TA functions. p53 originates from man or mouse (mu) as indicated. Beyond the cancer-related p53 mutants p53(143A), p53(175H), p53(237l), p53(248Q), p53(248W), p53(273H), p53(273P), p53(281G), the temperature-sensitive mutants mup53(135V) and p53(138V), the alternatively spliced (AS) form from mice, and variants with shortened C-terminus were analysed (p53(1-363), p53 (1-333)). Recent investigations with mutants carrying amino-acid exchanges in the TA domain $(\mathrm{p} 53(22 \mathrm{Q}, 23 \mathrm{~S}))$ and the RPA interaction domain $(\mathrm{p} 53(48 \mathrm{H}, 49 \mathrm{H}), \mathrm{p} 53(53 \mathrm{~S}, 54 \mathrm{~S}))$, respectively, provided final proof for separation of functions

thereby rescuing the replication fork. ${ }^{114}$ The importance of HR in restoring replication forks in mitotically growing cells offers an explanation why loss of central HR functions is incompatible with life in the corresponding knockout mice. ${ }^{86}$ Two studies demonstrated that p53 inhibits HR not only following the introduction of an artificial DSB, but counteracts hyperrecombination also in response to replication fork stalling. ${ }^{15,116}$ This replication associated activity may also explain earlier observations indicating that TP53 deficient cells must proceed through $\mathrm{S}$ phase under conditions that induce DNA breakage for genetic instability to occur. ${ }^{117}$ Consistently, two groups further noticed that p53 prevents the accumulation of DSBs at stalled-replication forks induced by UV or hydroxyurea treatment. ${ }^{118,119}$ When DNA replication is blocked, p53 becomes phosphorylated on serine 15 and associates with key enzymes of HR such as the MRN complex, Rad51, and Rad54. ${ }^{105,112,120,121}$ Notably, during replication arrest p53 remains inactive in transcriptional transactivation, ${ }^{121,122}$ supporting the idea that $p 53$ is involved in HR regulatory functions unrelated to transcriptional transactivation activities.

\section{HR Surveillance by p53 as the Mechanistic Basis of the Antirecombinogenic Effect}

So far, HR repression has been the best understood direct function of p53 in DNA repair. Important clues to the molecular mechanism have come from the results of pull-down and electrophoretic mobility shift assays with recombinant proteins, immunoprecipitation experiments with mammalian cell extracts, as well as immunofluorescence microscopy colocalisation studies. Thus, direct physical interactions between Rad51 (amino acids 125-220) and wild-type p53 (amino acids 94-160 and 264-315), were demonstrated. The p53 point mutants p53(135Y), p53(249S), and p53(273H) showed weaker interactions. ${ }^{105,112,123-125}$ p53 has also been reported to interact with the products of the two major hereditary breast cancer susceptibility genes, Brca1 and breast cancer-related 2 protein (Brca2 protein), which form stable complexes with Rad51 in the nuclei of mitotic and meiotic cells. ${ }^{52,126,127}$ Brca1 serves as a molecular scaffold for the assembly of the HR repair complex, Brca2 facilitates Rad51 filament assembly. ${ }^{128}$ Other DSB repair proteins reported to interact with p53 are Rad54, ${ }^{112}$ RPA, ${ }^{129}$ and Bloom's syndrome protein (Blm) and Werner's Syndrome Protein (Wrn), two helicases with unwinding activities on Holliday junctions in vitro. ${ }^{130-132}$

Using recombination substrates that allowed to distinguish between DSB repair mechanisms initiated by Rad51-dependent strand invasion, that is mostly gene conversion, and nonconservative events, that is mostly SSA, indicated an interference of p53 with HR involving strand invasion. ${ }^{104,108}$ Linke et al. ${ }^{112}$ confirmed the dependence of p53's antirecombinogenic function on the Rad51 pathway when applying expression plasmids for dominant-negative Rad51, for mutant Rad51(186P), which cannot bind p53, and for 
dominant-negative Rad54. As was suspected from the interaction of p53 with the highly conserved region within Rad51, which is required for homo-oligomerisation of the Escherichia coli homologue RecA, wild-type p53, but not p53(273H), was observed to influence the formation of Rad51 polymers. Biochemical investigations demonstrated that p53 inhibits Rad51-mediated strand exchange in vitro. ${ }^{133}$ The results suggested that wild-type but not mutant p53 may interfere with Rad51 activities at two stages. First, via direct protein-protein interactions p53 inhibits Rad51-ssDNA filament formation and, therefore, hinders Rad51 from initiating strand exchange. Second, p53 inhibits continued strand exchange, and, thus counteracts branch migration promoted by Rad51. p53 mutants, p53 $(48 \mathrm{H}, 49 \mathrm{H})$ and $\mathrm{p} 53(53 \mathrm{~S}, 54 \mathrm{~S})$, with amino-acid exchanges which specifically abolished RPA binding, but not transcriptional transactivation, failed to suppress HR in cellbased recombination assays. This indicated that binding of p53 to RPA is also necessary for HR repression. ${ }^{129}$ In a recent report by Yun et al., ${ }^{134}$ p53 was proposed to additionally affect Rad51-independent, nonconservative DSB repair, although further experiments are required to strengthen this interesting finding. Mechanistically, it is not clear how p53 may regulate SSA events, since colocalisation studies demonstrated interactions of p53 with MRN-complexes, with Rad51, and with Rad54, whereas no significant association was seen with Rad52 which carries a central Rad51-independent role in SSA in addition to its auxiliary function in $\mathrm{HR}^{121}$

Taken together, cell-based recombination and protein association studies provided strong evidence for a role of p53 in Rad51-dependent HR. From the kinetics of the interaction of p53 with HR proteins, it is likely to be involved in the earliest steps of HR. ${ }^{121} \mathrm{HR}$ is considered an error-free DNA repair pathway, however, it can also produce genetic instability upon up- or deregulation. First clues to the biological meaning of this somewhat paradoxical activity of p53 directed against a fairly safe DNA repair activity came from observations indicating that $\mathrm{p} 53$ preferentially represses HR between certain mispaired DNA sequences. ${ }^{21}$ p53 was further discovered to specifically recognise preformed heteroduplex joints structurally resembling early recombination intermediates, particularly when comprising these mispairings. ${ }^{21,22,125}$ Already in $1996,{ }^{23}$ the discovery of a $3^{\prime}-5^{\prime}$ exonuclease activity had raised the question, whether p53 is involved in fidelity control mechanisms. Notably, p53 was then found to exonucleolytically attack DNA particularly during Rad51mediated strand transfer and to exhibit a DNA substrate preference for heteroduplex recombination intermediates with a further enhancement of the exonucleolytic activity for mispaired as compared to correctly paired heteroduplex DNA. ${ }^{125}$ Emphasising the importance of p53 DNA interactions in the regulation of strand exchange events, p53 was seen to inhibit branch migration of Holliday junctions in the absence of any recombinase as well as when promoted by the bacterial RuvAB branch migration enzyme. ${ }^{135}$ Together with the observed stabilisation of p53-DNA complexes after preassembly of Rad51-nucleoproteins, all these data suggested that the mechanism underlying HR inhibition by p53 involves stable interactions with and proofreading of the heteroduplex immediately after Rad51-mediated strand exchange (see Figure 3).
In contrast to the MMR and HR regulatory protein Msh2, which recognises $\mathrm{G}-\mathrm{T}$ single base mispairings best, mismatch recognition by $p 53$ has a preference for $A-G$ and $C-C$ mismatches. ${ }^{21,24,26,27,136}$ Strikingly, both Msh2 and p53 were described to interact with Holliday junctions, to associate with recombinative repair complexes containing factors like Rad51 and Rad50, to regulate BIm helicase, and to sense heterologies between the substrates during HR. ${ }^{21,120,137-139}$ Subramanian and Griffith ${ }^{140}$ further demonstrated that binding of p53 to Holliday junctions is stimulated by Msh2. These observations have led to a model where p53 and Msh2 play complementary or even synergistic roles in the fidelity control of $\mathrm{HR}$.

p53 mutant analyses revealed qualitative and quantitative correlation between HR repression and related biochemical activities. Thus, the integrity of the core domain is required for $\mathrm{HR}$ repression, recognition of the junction DNA structure, and exonuclease activity. p53 must be in the tetrameric form for effective execution of HR repression and stable heteroduplex DNA complex formation. As was similarly seen for sequencespecific DNA binding, the C-terminal 30 amino acids of p53 negatively regulate heteroduplex joint binding and HR repression, an effect which can be neutralised by concurrent mismatch recognition, truncation, and post-translational modification of serine $392 .^{14,15,22,23,25,30,125,141}$ Notably, residues 373-383 are critical for Blm and Wrn interactions, but are dispensable for HR repression, which is why a major role of these enzymes in the execution of the p53-dependent antirecombinogenic effect is rather unlikely. ${ }^{30,109,132}$ Moreover, cell-based studies revealed a complementary rather than an epistatic relationship for p53 and BIm in the suppression of HR. ${ }^{105}$ On the other hand, p53 was reported to counteract Holliday junction unwinding by BIm and Wrn in vitro, and to inhibit Wrn exonuclease activity on forked duplex DNA. ${ }^{132,142}$ Additionally, immunoprecipitation and immunofluorescence microscopy data from Harris and co-workers ${ }^{105}$ showed that Blm, Rad51, and p53 phosphorylated on serine 15 (p53pSer15) interact during replication arrest and found BIm to be necessary for efficient accumulation of p53 within Rad51 foci at stalled replication forks. It is of interest that p53 counteracts regression of replication forks promoted by Rad51 to form a Holliday junction. ${ }^{133}$ In the next step, p53 also inhibits branch migration of the Holliday junction, thus, preventing reversal of regression to restart replication. Both regression of replication forks and reversal of regression may as well be executed by $\mathrm{BIm}$ or $\mathrm{Wrn},{ }^{105,143}$ and regulated by p53 (see Figure 3). Therefore, the possibility remains that p53 cooperates with $\mathrm{BIm}$ and/or Wrn in recombination surveillance particularly during replicational stress to protect stalled replication forks from collapsing into a substrate for $\mathrm{HR}$ and to destroy aberrant recombination intermediates.

From the colocalisation data of Restle et al. ${ }^{121}$ it is conceivable that at later stages Blm-p53 interactions might play an additional role in checkpoint signalling at persistently stalled replication forks. This scenario is especially interesting, since BIm also recruits 53Bp1 to replication fork lesions and facilitates physical interaction between p53 and p53 binding protein 1 (53Bp1), a recruiting factor for Atm targeting to DSBs. ${ }^{144,145}$ Blm-p53 interactions most likely promote phosphorylation of p53 through Atm and Atr, which in turn may 
DSB

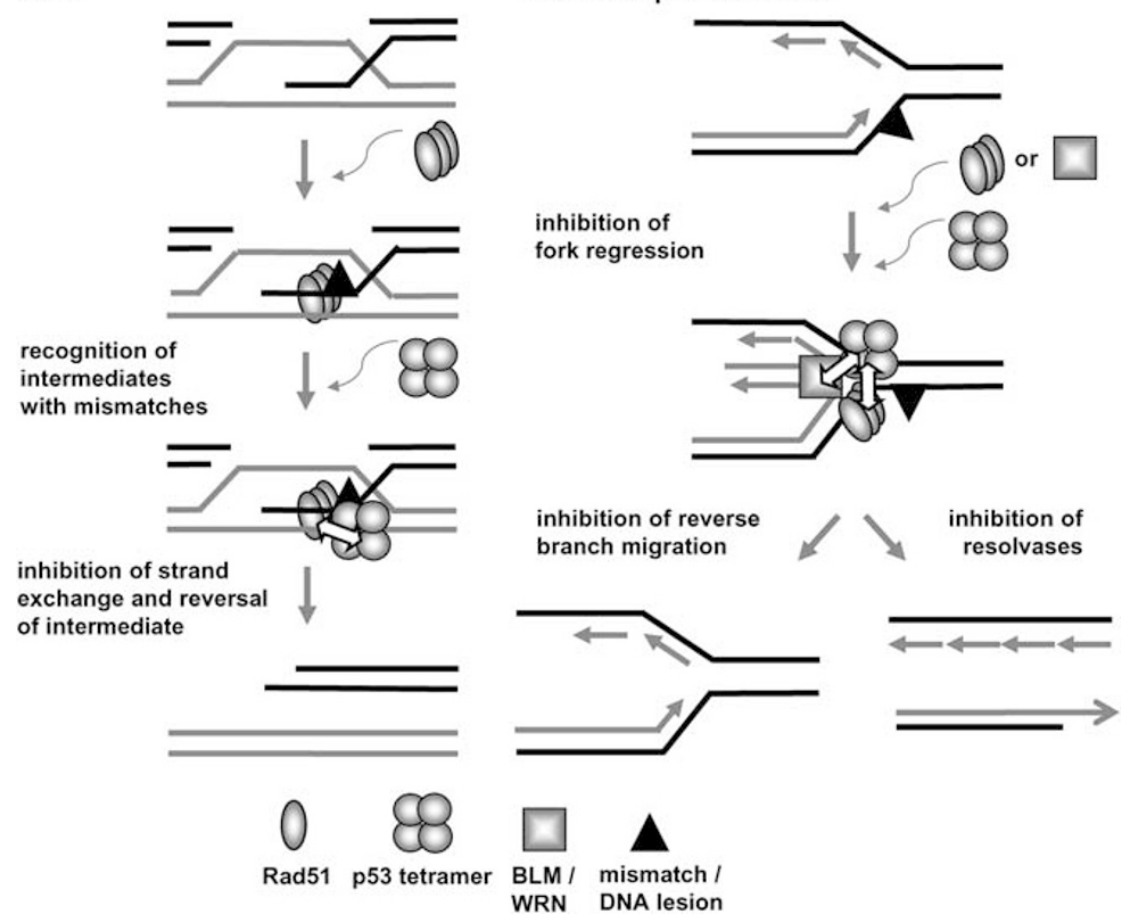

Figure 3 Model for the regulation of HR at DSBs and stalled replication forks by p53. Biochemical and cell-based data indicate that p53 represses Rad51-dependent $\mathrm{HR}$, particularly when recognising mismatches after the formation of heteroduplex joints. ${ }^{21,22,112,133}$ Strand exchange is blocked by direct contacts with Rad51 and intermediate DNA structures. DNA recombination intermediates are reversed by exonucleolytic processing. When encountering a DNA lesion, the replication fork stalls. Spontaneous, Rad51- or Blm/Wrn-mediated replication fork regression will generate a so-called chicken foot structure, thereby shifting the lesion into a DNA duplex for DNA repair. Regression of the replication fork will allow restart of replication. p53 recognises this Holliday junction-like structure and controls the generation and branch migration of the replication fork as well as its resolution, to prevent error-prone DSB repair and to cause replication pausing until the DNA lesion is repaired ${ }^{133,135}$

stabilise complexes with other DSB repair proteins like Rad51, Rad54, and RPA. A recent study also showed that BIm itself is required for optimal activation of Atm, the kinase which regulates DSB repair proteins and induces checkpoint signalling. ${ }^{145}$

\section{Evidence for a Regulatory Role of p53 in NHEJ}

With respect to a possible involvement of p53 in NHEJ, results that initially appeared contradictory were reported. Thus, two groups observed an increase in rejoining of linearised plasmid DNA in the presence of wild-type or temperature-sensitive mutant p53. ${ }^{146,147}$ However, an inhibitory effect by $p 53$ became apparent in five other studies applying reporter gene reconstitution, integration, and in vitro end-joining assays, ${ }^{104,148-151}$ and with experimental results from Comet assays, showing that after the exposure to IR DSB rejoining increases with loss of wild-type p53 function. ${ }^{152}$ Inhibition of in vitro end-joining was also observed with the oncogenic mutant p53 $(175 \mathrm{H})$, whereas the phosphorylation-mimicking mutant p53(15D) failed to inhibit, thereby providing a first hint to a possible role of Atm-mediated p53 phosphorylation in the regulation of NHEJ. ${ }^{150}$ In an attempt to bring these contradictory results together Akyüz et al. ${ }^{104}$ proposed that p53 may particularly strongly inhibit microhomology-mediated NHEJ, that is proofread NHEJ. Microhomology-mediated NHEJ as compared to simple rejoining of compatible ends is generally error-prone, as it involves gain or loss of nucleotides at the break site. In support of this concept, both Lin et al. ${ }^{153}$ and Dahm-Daphi et al. ${ }^{151}$ noticed that p53 inhibits microhomology-mediated NHEJ and from their data hypothesised that it may even facilitate precise religation at a single cleavage site.

The NHEJ stimulatory effect observed by Tang et al. ${ }^{147}$ relied on the $\mathrm{C}$-terminal reannealing activity of $\mathrm{p} 53$. Interestingly, Selivanova and co-workers ${ }^{154}$ discovered that Cterminal recognition of terminal ssDNA overhangs facilitates simultaneous core domain binding, whereas interaction with gaps is inhibitory to core domain binding. Therefore, in one scenario p53 might stimulate error-free NHEJ by its ability to efficiently bind protruding DNA ends and catalyse dsDNA formation with complementary ssDNA, whereas unpaired gap regions may even trigger p53 facilitated denaturation of this type of non-B DNA structure, thereby resolving the errorprone NHEJ DNA structure. ${ }^{155}$ Additionally, p53 interacts with and may cooperate with helicases like Blm which inhibits error-prone NHEJ. ${ }^{156}$ Thus, in view of a fidelity control function of $\mathrm{p} 53$ in $\mathrm{HR}$, it is conceivable that p53 plays a similar role in NHEJ, either by mere recognition of heterologies and abrogation of the process or by exonucleolytic resolution of error-prone NHEJ structures, because p53 preferentially removes unpaired nucleotides at the $3^{\prime}$-DNA end. ${ }^{24,26,27,29}$ It will be one of the challenges of the future 
years to unveil the mechanistic basis of p53's surveillance function in NHEJ that significantly counteracts gross chromosomal rearrangements.

\section{p53 Participates in Novel Recombination Stimulatory Pathways}

In sharp contrast to the sequence-independent $\mathrm{HR}$ repression by $\mathrm{p} 53$, two recent SV40-based studies unveiled recombination stimulatory activities of p53 at distinct DNA elements. In the first work, ${ }^{157}$ it was discovered that p53 upregulates recombination at a fragment of the $R A R \alpha$ breakpoint cluster region, which comprises two perfect topoisomerase 1 recognition sequences. Treatment with the topoisomerase 1 inhibitor camptothecin indicated an epistatic relationship between p53 and topoisomerase 1 with respect to recombination enhancement. This stimulatory activity was not restricted to wild-type p53 but was similarly seen with mutant p53(138V) with impaired transcriptional transactivation activities, which suggested a direct role of p53 in HR stimulation. Previously, wild-type and mutant p53 were shown to form stable complexes with topoisomerase 1 and to enhance topoisomerase 1-mediated relaxation of supercoiled DNA. ${ }^{158,159}$ Moreover, Soe et al. ${ }^{160}$ noticed that p53 stimulates the formation of a double cleavage complex with two topoisomerase 1 molecules encompassing a DNA lesion. After the introduction of certain types of DNA lesions, such as caused by $\gamma$ irradiation, p53 may, therefore, maintain genomic stability by promoting homology-based repair via this newly discovered topoisomerase 1-dependent lesion excision mechanism and subsequent recombinative gap repair. Damage-specific processing via topoisomerase 1-p53 complexes might also explain earlier in vivo data with $\mathrm{X}$-ray treated mice showing elevated recombination frequencies for $T R P 53^{+/+}$mice compared with TRP53 ${ }^{-1-}$ mice. $^{161}$

In the second work, HR stimulation was found upon sequence-specific binding of wild-type p53 to the ribosomal gene cluster repeat (RGC repeat). ${ }^{162}$ The consensus DNAbinding defective mutant p53(138V) exhibited a significantly reduced stimulatory effect, although p53(138V) is active in sequence-independent $\mathrm{HR}$ repression and topoisomerase 1-mediated HR stimulation. Interestingly, the TGCCT repeat present in the RGC has not been connected to transactivating functions, rather to replication origins. ${ }^{163}$ Consistently, HR increase was not seen with replication incompetent plasmid substrates and correlated with a replicational delay of viral genomes. Thus, different from the stimulatory mechanism strictly involving topoisomerase 1 , here, a delay of replication fork progression is likely to promote replication-associated recombination. From the DNA binding data of Brazdova et al. ${ }^{164}$ it is conceivable that oligomeric p53, tightly bound to the RGC repeat on supercoiled DNA, represents an obstacle to replication fork progression, thereby triggering strand exchange. Thus, although p53 inhibits recombination induced by aphidicolin or hydroxyurea treatment, ${ }^{115,116}$ p53, when sequence-specifically bound to DNA, stimulates recombination. One possible explanation for this apparently conflicting role of p53 is that upon replication pausing in the absence of DNA breakage p53 will not or only partially be relocalised from the consensus binding to the recombination site. A stalled replication fork alone may be insufficient to induce the recombination inhibitory activity of $\mathrm{p53}$, as was similarly proposed for the induction of the SOS response in E. coli. ${ }^{114}$ In agreement with this idea, we noticed that p53 regained recombination inhibitory activities at the RGC binding site upon camptothecin-mediated DNA breakage. In analogy to the role of the Fob1 protein in yeast, the biological meaning of this newly discovered activity could be that p53 plays a role in rDNA copy number adjustment and sequence homogenisation. Further analysis will be required to fully understand the potential HR stimulatory role of p53 when sequence-specifically bound to nontransactivating DNA-elements.

\section{Regulation of DNA Repair as a Potential Tumour-suppressor Function?}

Progression of mammalian cells to malignancy is a multistep process that involves the sequential accumulation of mutations in important regulatory genes. It is also generally agreed upon that 553 represents a central factor for the maintenance of genome stability, and, consequently, for the suppression of cancer. Some of the reports in the literature indicate that mechanisms alternative to growth and death control must contribute to tumour suppression by $\mathrm{p} 53$. Thus, different from TRP53 knockout mice, which die between 4 and 6 months, usually due to lymphomas and sarcomas, ${ }^{165}$ mice nullizygous for CDKN1A did not display increased cancer susceptibilities. $^{166}$ However, even the concept that p53-mediated apoptosis in addition to the transcriptional upregulation of cell-cycle regulatory genes prevents tumorigenesis turned out to be incomplete. This was indicated by the absence of tumour formation after treatment of mice with $\gamma$-ray and Pifithrin $\alpha$, a compound which inactivates transcriptional transactivating and proapoptotic functions of p53. ${ }^{167}$ Moreover, using a myc mouse model with or without concomitant apoptosis disruption by BCL2 overexpression versus TRP53 knockout, Schmitt et al. ${ }^{168}$ noticed an intermediate overall survival time for $B C L 2$ overexpression. As Myc impairs p53-mediated transactivation of $C D K N 1 A,{ }^{169}$ this outcome suggested that among the plethora of tumour-suppressor functions exhibited by p53, one function was still missing. Notably, the authors also saw that during lymphomagenesis in mice, apoptosis is the only p53 function that is selected against. Different from transgenic mice harbouring a mutant TRP53 gene which develop lymphomas and sarcomas, female Li-Fraumeni patients with an inherited defect in the TP53 gene are characterised by a predominance of breast carcinomas. ${ }^{98,170}$ Therefore, different modifier genes involved in cancer formation may be active in mice and man, and may also cause differences concerning the importance of single tumour-promoting activities of mutant p53. Consequently, we propose that defective DNA repair activities due to mutations in the TP53 gene underlie the high rate of chromosomal aberrations associated with the Li-Fraumeni syndrome and contribute to the formation of early onset neoplasms and multiple primary tumours.

DNA repair defects such as in NER and BER may, depending on the cell type, either compromise cellular survival 


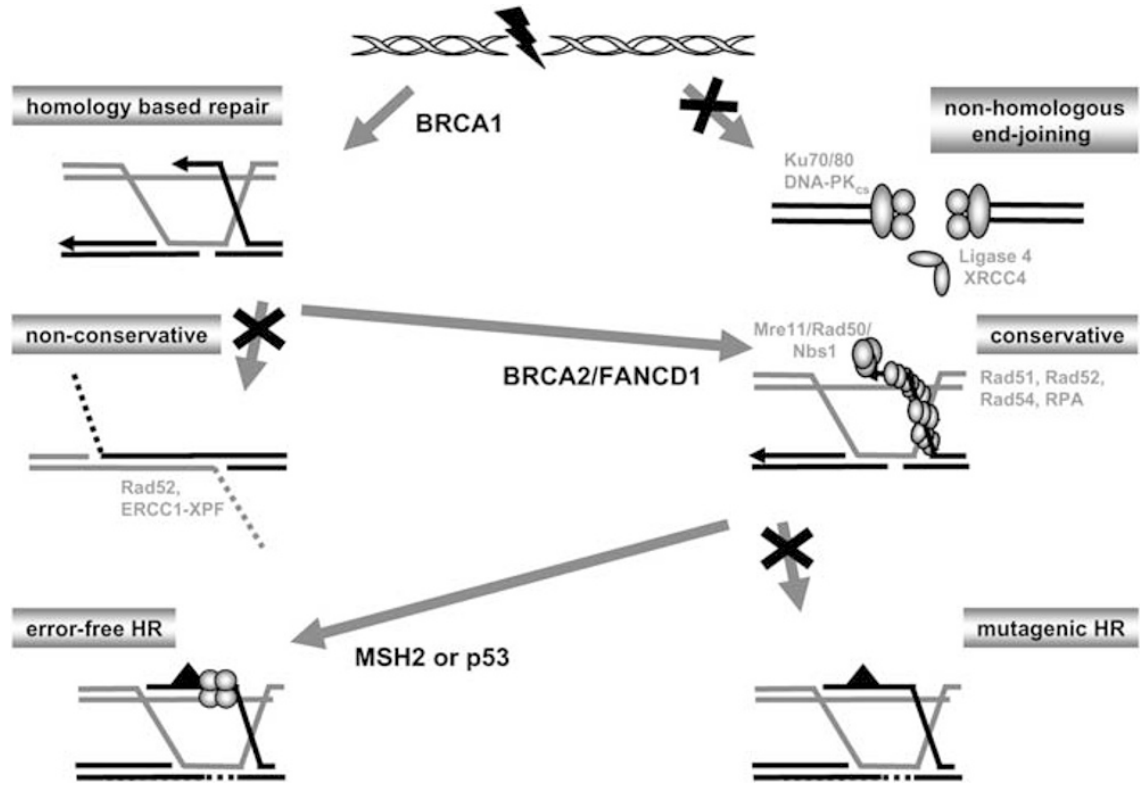

Figure 4 Hierarchy in the fidelity control of DSB repair. After the introduction of a DSB into the cellular genome, the specific repair pathway will be selected by a series of surveillance factors. First, Brca1 channels DSB repair into the homology-based pathway, thereby avoiding mutations from NHEJ. Second, Brca2, which is identical to the Fanconi anemia protein Fanc D1, promotes conservative HR rather than deleterious SSA events. ${ }^{93}$ Finally, Msh2 and p53 repress HR between divergent sequences, thus, resulting in error-free reconstitution of the genomic sequence $e^{21,138}$

or contribute to the enhanced carcinogenesis associated with p53 loss of function when the cells can no longer be eliminated by apoptosis due to the mutant TP53 status. Excision and recombinative DNA repair are coordinated, because incomplete excision repair intermediates are shuttled into $\mathrm{HR}^{80}$ Clearly, error-prone DSB repair increases the cancer risk, as is illustrated best by the large number of breast cancer susceptibility syndromes that are related to defects in HR surveillance factors. ${ }^{171}$ Within the hierarchy of DSB repair surveillance, Brca1 directs repair from NHEJ into the safer, homology-based pathway, at the next step Brca2 promotes nonmutagenic HR. ${ }^{93}$ Msh2 and p53 may then be responsible for the identification and alignment of perfectly homologous sequences to ensure error-free HR (see Figure 4). Indeed, TP53 mutant as compared to wild-type cells not only display elevated LOH frequencies but also an increased length of exchange tracts, indicating reduced homology surveillance functions. ${ }^{95}$ Moreover, two studies unveiled that p53 preferentially represses recombination between sequences with short homologies, that is with extensively divergent sequences. ${ }^{104,172} A$ threshhold of homology length for recombination in mammalian cells has been described, so that p53 may contribute to the barrier for recombination between repetitive sequences in the genome.

The comparison of $T R P 53^{+/-}$mouse fibroblasts to their TRP53 ${ }^{+1+}$ counterparts showed that not only loss of but also reduced dosage of $\mathrm{p} 53$ promotes $\mathrm{HR} .{ }^{173}$ Thus, haploinsufficiency of TP53 for HR repression is a likely explanation for the mutator phenotype in LFS cells that drives early tumour formation even without complete TP53 loss. Different from the loss-of-function phenotype, several studies, using an isogenic set of human lymphoblastoid cells, indicated that aberrant DSB repair processes occur more frequently in TP53 mutant than TP53 null cells suggesting a gain-of-function for the mutant proteins. ${ }^{95}$ The newly discovered recombination stimulatory activity of p53 that may be connected to topoisomerase 1-dependent excision repair is a good candidate for this gain-of-function phenotype. ${ }^{157}$ Thus, failure to suppress aberrant HR coupled to the remaining capacity to stimulate DNA exchange via this topoisomerase 1 repair pathway would be expected to generate a gain-of-function phenotype in recombination, which also could explain the rise in gene amplification observed with some mutant p53 proteins. Specific recruitment and differential modification of the p53 molecule might coordinate the different repair-related activities, as suggested by the tightly regulated interactions of wild-type p53 with topoisomerase 1 in response to DNA damage. In conclusion, we propose that wild-type p53 performs caretaker functions by global suppression of mutagenic DNA exchange events as well as by stimulatory interactions with topoisomerase 1 at specific DNA lesions. The analyses of different cancer-related p53 mutations with respect to the participation in recombination-inhibitory versus -stimulatory pathways will be important in describing the complexity of p53 activities during tumorigenesis.

\section{References}

1. Hollstein M, Sidransky D, Vogelstein B and Harris CC (1991) p53 mutations in human cancers. Science 253: 49-53.

2. deFromentel $C$ and Soussi T (1992) TP53 tumor suppressor gene: a model for investigating human mutagenesis. Genes Chromosomes Cancer 4: 1-15.

3. Lane DP (1992) p53, guardian of the genome. Nature 358: 15-16.

4. Levine AJ (1997) p53, the cellular gatekeeper for growth and division. Cell 88: 323-331. 
5. Saito S, Yamaguchi H, Higashimoto Y, Chao C, Xu Y, Fornace Jr AJ, Appella $E$ and Anderson CW (2003) Phosphorylation site interdependence of human p53 post-translational modifications in response to stress. J. Biol. Chem. 278: 37536-37544.

6. Vaziri H, West MD, Allsopp RC, Davison TS, Wu YS, Arrowsmith CH, Poirier GG and Benchimol S (1997) ATM-dependent telomere loss in aging human diploid fibroblasts and DNA damage lead to the post-translational activation of p53 protein involving poly(ADP-ribose) polymerase. EMBO J. 16: 6018-6033.

7. Wang X, Ohnishi K, Takahashi A and Ohnishi T (1998) Poly(ADP-ribosyl)ation is required for p53-dependent signal transduction induced by radiation. Oncogene 17: 2819-2825.

8. Livingstone LR, White A, Sprouse J, Livanos E, Jacks T and Tlsty TD (1992) Altered cell cycle arrest and gene amplification potential accompany loss of wildtype p53. Cell 70: 923-935.

9. Harvey M, Sands AT, Weiss RS, Hegi ME, Wiseman RW, Pantazis $P$, Giovanella BC, Tainsky MA, Bradley A and Donehower LA (1993) In vitro growth characteristics of embryo fibroblasts isolated from p53-deficient mice. Oncogene 8: 2457-2467.

10. Ishizaki K, Ejima $Y$, Matsunaga $T$, Hara R, Sakamoto A, Ikenaga M, Ikawa $Y$ and Aizawa S (1994) Increased UV-induced SCEs but normal repair of DNA damage in p53-deficient mouse cells. Int. J. Cancer 58: 254-257.

11. Schwartz JL and Russell KJ (1999) The effect of functional inactivation of TP53 by HPV-E6 transformation on the induction of chromosome aberrations by gamma rays in human tumor cells. Radiat. Res. 151: 385-390.

12. Rogan EM, Bryan TM, Hukku B, Maclean K, Chang AC, Moy EL, Englezou A Warneford SG, Dalla-Pozza L and Reddel RR (1995) Alterations in p53 and p16INK4 expression and telomere length during spontaneous immortalization of Li-Fraumeni syndrome fibroblasts. Mol. Cell. Biol. 15: 4745-4753.

13. Bakalkin G, Yakovleva T, Selivanova G, Magnusson KP, Szekely L, Kiseleva E, Klein G, Terenius L and Wiman KG (1994) P53 binds single-stranded DNA ends and catalyzes DNA renaturation and strand transfer. Proc. Natl. Acad. Sci. USA 91: 413-417.

14. Jayaraman J and Prives $C$ (1995) Activation of p53 sequence-specific DNA binding by short single strands of DNA requires the p53 C-terminus. Cell 81 : 1021-1029.

15. Lee S, Elenbaas B, Levine A and Griffith J (1995) p53 and its $14 \mathrm{kDa}$ C-terminal domain recognize primary DNA damage in the form of insertion/ deletion mismatches. Cell 81: 1013-1020.

16. Reed M, Woelker B, Wang $P$, Wang $Y$, Anderson ME and Tegtmeyer $P$ (1995) The $C$-terminal domain of $p 53$ recognizes DNA damaged by ionizing radiation. Proc. Natl. Acad. Sci. USA 92: 9455-9459.

17. Oberosler $P$, Hloch $P$, Ramsperger U and Stahl H (1993) p53-catalyzed annealing of complementary single-stranded nucleic acids. EMBO J. 12: 2389-2396.

18. Brain R and Jenkins JR (1994) Human p53 directs DNA strand reassociation and is photolabelled by 8-azido ATP. Oncogene 9: 1775-1780.

19. Jean D, Gendron D, Delbecchi L and Bourgaux P (1997) p53-mediated DNA renaturation can mimic strand exchange. Nucleic Acids Res. 25: 4004-4012.

20. Lee S, Cavallo L and Griffith J (1997) Human p53 binds Holliday junctions strongly and facilitates their cleavage. J. Biol. Chem. 272: 7532-7539.

21. Dudenhöffer C, Kurth M, Janus F, Deppert W and Wiesmüller L (1998) Dissociation of the recombination control and the sequence-specific transactivation function of p53. Mol. Cell. Biol. 18: 5332-5342.

22. Janz $C$, Süsse $S$ and Wiesmüller $L$ (2002) p53 and recombination intermediates: role of tetramerization at DNA junctions in complex formation and exonucleolytic degradation. Oncogene 21: 2130-2140.

23. Mummenbrauer $T$, Janus $F$, Müller $B$, Wiesmüller $L$, Deppert $W$ and Grosse $F$ (1996) P53 exhibits $3^{\prime}$-'to 5'-exonuclease activity. Cell 85: 1089-1099.

24. Huang P (1998) Excision of mismatched nucleotides from DNA: a potential mechanism for enhancing DNA replication fidelity by the wildtype p53 protein. Oncogene 17: 261-270.

25. Janus $F$, Albrechtsen N, Knippschild $U$, Wiesmüller L, Grosse $F$ and Deppert W (1999) Different regulation of the core domain activities $3^{\prime}$ to $5^{\prime}$ exonuclease and sequence-specific DNA binding. Mol. Cell. Biol. 19: $2155-2168$

26. Skalski V, Lin ZY, Choi BY and Brown KR (2000) Substrate specificity of the p53-associated 3'-5' exonuclease. Oncogene 19: 3321-3329.

27. Bakhanashvili M (2001) Exonucleolytic proofreading by p53 protein. Eur. J. Biochem. 268: 2047-2054.
28. Shakked Z, Yavnilovitch M, Kalb Gilboa AJ, Kessler N, Wolkowicz R, Rotter V and Haran TE (2002) DNA binding and 3'-5' exonuclease activity in the murine alternatively-spliced p53 protein. Oncogene 21: 5117-5126.

29. Melle $C$ and Nasheuer HP (2002) Physical and functional interactions of the tumor suppressor protein p53 and DNA polymerase alpha-primase. Nucleic Acids Res. 30: 1493-1499.

30. Dudenhöffer C, Rohaly G, Will K, Deppert W and Wiesmüller L (1999) Dissociation of the recombination control and the sequence-specific transactivation function of p53. Oncogene 18: 5773-5784.

31. Albrechtsen N, Dornreiter I, Grosse F, Kim E, Wiesmuller L and Deppert W (1999) Maintenance of genomic integrity by p53: complementary roles for activated and non-activated p53. Oncogene 18: 7706-7717.

32. Bertrand P, Saintigny $Y$ and Lopez BS (2004) P53's double life: transactivation-independent repression of homologous recombination. Trends Genet. 20: 235-243.

33. Sengupta $S$ and Harris CC (2005) p53: traffic cop at the crossroads of DNA repair and recombination. Nat. Rev. Mol. Cell Biol. 6: 44-55.

34. Zhao R, Gish K, Murphy M, Yin Y, Notterman D, Hoffman WH, Tom E, Mack DH and Levine AJ (2000) Analysis of p53-regulated gene expression patterns using oligonucleotide arrays. Genes Dev. 14: 981-993.

35. Vogelstein B, Lane D and Levine AJ (2000) Surfing the p53 network. Nature 408: 307-310.

36. Nakano K and Vousden KH (2001) PUMA, a novel proapoptotic gene, is induced by p53. Mol. Cell 7: 683-694.

37. Baptiste $N$ and Prives C (2004) p53 in the cytoplasm: a question of overkill? Cell 116: 487-489.

38. Hoeijmakers JHJ (2001) Genome maintenance mechanisms for preventing cancer. Nature 411: 366-373.

39. Schärer OD (2003) Chemistry and biology of DNA repair. Angew. Chem. Int. Ed. Engl. 42: 2946-2974.

40. Ford JM and Hanawalt PC (1995) Li-Fraumeni syndrome fibroblasts homozygous for p53 mutations are deficient in global DNA repair but exhibit normal transcription-coupled repair and enhanced UV resistance. Proc. Natl. Acad. Sci. USA 92: 8876-8880.

41. Zhu Q, Wani MA, El-Mahdy M and Wani AA (2000) Decreased DNA repair efficiency by loss or disruption of $p 53$ function preferentially affects removal of cyclobutane pyrimidine dimers from non-transcribed strand and slow repair sites in transcribed strand. J. Biol. Chem. 275: 11492-11497.

42. Hwang BJ, Ford JM, Hanawalt PC and Chu G (1999) Expression of the p48 xeroderma pigmentosum gene is p53-dependent and is involved in global genomic repair. Proc. Natl. Acad. Sci. USA 96: 424-428.

43. Adimoolam S and Ford JM (2002) p53 and DNA damage-inducible expression of the xeroderma pigmentosum group $\mathrm{C}$ gene. Proc. Natl. Acad. Sci. USA 99: $12985-12990$.

44. Tan $T$ and Chu G (2002) p53 Binds and activates the xeroderma pigmentosum DDB2 gene in humans but not mice. Mol. Cell. Biol. 22: 3247-3254.

45. Amundson SA, Patterson A, Do KT and Fornace Jr AJ (2002) A nucleotide excision repair master-switch: $p 53$ regulated coordinate induction of global genomic repair genes. Cancer Biol. Ther. 1: 145-149.

46. McKay BC, Ljungman M and Rainbow AJ (1999) Potential roles for p53 in nucleotide excision repair. Carcinogenesis 20: 1389-1396.

47. Smith ML, Chen IT, Zhan Q, Bae I, Chen CY, Gilmer TM, Kastan MB, O'Connor PM and Fornace Jr AJ (1994) Interaction of the p53-regulated protein Gadd45 with proliferating cell nuclear antigen. Science 266: 1376-1380

48. Smith ML, Ford JM, Hollander MC, Bortnick RA, Amundson SA, Seo YR, Deng CX, Hanawalt PC and Fornace Jr AJ (2000) p53-mediated DNA repair responses to UV radiation: studies of mouse cells lacking p53, p21, and/or gadd45 genes. Mol. Cell. Biol. 20: 3705-3714.

49. Tanaka H, Arakawa H, Yamaguchi T, Shiraishi K, Fukuda S, Matsui K, Takei $Y$ and Nakamura $Y(2000)$ A ribonucleotide reductase gene involved in a p53-dependent cell-cycle checkpoint for DNA damage. Nature 404: $42-49$.

50. MacLachlan TK, Takimoto R and El-Deiry WS (2002) BRCA1 directs a selective p53-dependent transcriptional response towards growth arrest and DNA repair targets. Mol. Cell. Biol. 22: 4280-4292.

51. Adimoolam S and Ford JM (2003) p53 and regulation of DNA damage recognition during nucleotide excision repair. DNA Repair 2: 947-954. 
52. Ouchi T, Monteiro AN, August A, Aaronson SA and Hanafusa H (1998) BRCA1 regulates p53-dependent gene expression. Proc. Natl. Acad. Sci. USA 95: 2302-2306.

53. Venkitaraman AR (2002) Cancer susceptibility and the functions of BRCA1 and BRCA2. Cell 108: 171-182.

54. Rafferty JA, Clarke AR, Sellappan D, Koref MS, Frayling IM and Margison GP (1996) Induction of murine O6-alkylguanine-DNA-alkyltransferase in response to ionising radiation is p53 gene dose dependent. Oncogene 12: 693-697.

55. Grombacher T, Eichhorn U and Kaina B (1998) p53 is involved in regulation of the DNA repair gene 06-methylguanine-DNA methyltransferase (MGMT) by DNA damaging agents. Oncogene 17: 845-851.

56. Barnes DE and Lindahl T (2004) Repair and genetic consequences of endogenous DNA base damage in mammalian cells. Annu. Rev. Genet. 38 445-476.

57. Zurer I, Hofseth LJ, Cohen Y, Xu-Welliver M, Hussain SP, Harris CC and Rotter $V$ (2004) The role of p53 in base excision repair following genotoxic stress. Carcinogenesis 25: 11-19.

58. Lu X, Nguyen TA, Appella E and Donehower LA (2004) Homeostatic regulation of base excision repair by a p53-induced phosphatase: linking stress response pathways with DNA repair proteins. Cell Cycle 3 : 1363-1366.

59. Scherer SJ, Maier SM, Seifert M, Hanselmann RG, Zang KD, MullerHermelink HK, Angel P, Welter C and Schartl M (2000) p53 and c-Jun functionally synergize in the regulation of the DNA repair gene hMSH2 in response to UV. J. Biol. Chem. 275: 37469-37473

60. Warnick CT, Dabbas B, Ford CD and Strait KA (2001) Identification of a p53 response element in the promoter region of the $\mathrm{hMSH} 2$ gene required for expression in A2780 ovarian cancer cells. J. Biol. Chem. 276: 27363-27370.

61. Chen J and Sadowski I (2005) Identification of the mismatch repair genes PMS2 and MLH1 as p53 target genes by using serial analysis of binding elements. Proc. Natl. Acad. Sci. USA 102: 4813-4818.

62. Evans $E$ and Alani $E$ (2000) Roles for mismatch repair factors in regulating genetic recombination. Mol. Cell. Biol. 20: 7839-7844.

63. Marti TM, Kunz C and Fleck O (2002) DNA mismatch repair and mutation avoidance pathways. J. Cell. Physiol. 191: 28-41.

64. Jiricny J and Nyström-Lahti M (2000) Mismatch repair defects in cancer. Curr Opin. Genet. Dev. 10: 157-161.

65. Stojic L, Brun R and Jiricny $\mathrm{J}$ (2004) Mismatch repair and DNA damage signalling. DNA Repair 3: 1091-1101.

66. Liebetrau W, Budde A, Savoia A, Grummt F and Hoehn H (1997) p53 activates Fanconi anemia group $C$ gene expression. Hum. Mol. Genet. 6 : 277-283.

67. Myung K, Braastad C, He DM and Hendrickson E (1998) KARP-1 is induced by DNA damage in a p53- and ataxia telangiectasia mutated-dependent fashion. Proc. Natl. Acad. Sci. USA 95: 7664-7669.

68. Smith ML, Chen IT, Zhan Q, O'Connor PM and Fornace Jr AJ (1995) Involvement of the p53 tumor suppressor in repair of u.v.-type DNA damage. Oncogene 10: 1053-1059.

69. Wang XW, Yeh H, Schaeffer L, Roy R, Moncollin V, Egly JM, Wang Z, Freidberg EC, Evans MK, Taffe BG, Bohr VA, Weeda G, Hoeijmakers JHJ, Forrester K and Harris CC (1995) p53 modulation of TFIIH-associated nucleotide excision repair activity. Nat. Genet. 10: 188-195.

70. Leveillard T, Andera L, Bissonnette N, Schaeffer L, Bracco L, Egly JM and Wasylyk B (1996) Functional interactions between p53 and the TFIIH complex are affected by tumour-associated mutations. EMBO J. 15: 1615-1624.

71. Rubbi CP and Milner $\mathrm{J}$ (2003) p53 is a chromatin accessibility factor for nucleotide excision repair of DNA damage. EMBO J. 22: 975-986.

72. Offer H, Wolkowicz R, Matas D, Blumenstein S, Livneh Z and Rotter V (1999) Direct involvement of $p 53$ in the base excision repair pathway of the DNA repair machinery. FEBS Lett. 450: 197-204.

73. Offer H, Milyavsky M, Erez N, Matas D, Zurer I, Harris CC and Rotter V (2001) Structural and functional involvement of $\mathrm{p} 53$ in BER in vitro and in vivo. Oncogene 20: 581-589.

74. Offer H, Erez N, Zurer I, Tang X, Milyavsky M, Goldfinger N and Rotter V (2002) The onset of p53-dependent DNA repair or apoptosis is determined by the level of accumulated damaged DNA. Carcinogenesis 23: 1025-1032.

75. Zhou J, Ahn J, Wilson SH and Prives C (2001) A role for p53 in base excision repair. EMBO J. 20: 914-923.
76. Jayaraman L, Murthy KG, Zhu C, Curran T, Xanthoudakis S and Prives $C$ (1997) Identification of redox/repair protein Ref-1 as a potent activator of p53. Genes Dev. 11: 558-570.

77. Gaiddon C, Moorthy NC and Prives C (1999) Ref-1 regulates the transactivation and pro-apoptotic functions of p53 in vivo. EMBO J. 18 5609-5621.

78. Seemann $S$ and Hainaut $P$ (2005) Roles of thioredoxin reductase 1 and APE/ Ref- 1 in the control of basal p53 stability and activity. Oncogene 24 3853-3863.

79. Seo YR, Fishel ML, Amundson S, Kelley MR and Smith ML (2002) Implication of p53 in base excision DNA repair: in vivo evidence. Oncogene 21: 731-737.

80. Sobol RW, Kartalou M, Almeida KH, Joyce DF, Engelward BP, Horton JK, Prasad R, Samson LD and Wilson SH (2003) Base excision repair intermediates induce p53-independent cytotoxic and genotoxic responses. J. Biol. Chem. 278: 39951-39959.

81. de Souza-Pinto NC, Harris CC and Bohr VA (2004) p53 functions in the incorporation step in DNA base excision repair in mouse liver mitochondria. Oncogene 23: 6559-6568

82. Robles Al, Wang XW and Harris CC (1999) Drug-induced apoptosis is delayed and reduced in XPD lymphoblastoid cell lines: possible role of TFIIH in p53-mediated apoptotic cell death. Oncogene 18: 4681-4688.

83. Ljungman M and Lane DP (2004) Transcription - guarding the genome by sensing DNA damage. Nat. Rev. Cancer 4: 727-737.

84. Miller SD, Moses K, Jayaraman L and Prives C (1997) Complex formation between p53 and replication protein $A$ inhibits the sequence-specific DNA binding of p53 and is regulated by single-stranded DNA. Mol. Cell. Biol. 17: 2194-2201.

85. Abramova NA, Russell J, Botchan M and Li R (1997) Interaction between replication protein $A$ and $p 53$ is disrupted after UV damage in a DNA repairdependent manner. Proc. Natl. Acad. Sci. USA 94: 7186-7191.

86. Valerie K and Povirk LF (2003) Regulation and mechanisms of mammalian double-strand break repair. Oncogene 22: 5792-5812.

87. Lees-Miller SP and Meek K (2003) Repair of DNA double strand breaks by non-homologous end joining. Biochimie 85: 1161-1173.

88. Riballo E, Kuhne M, Rief N, Doherty A, Smith GC, Recio MJ, Reis C, Dahm K, Fricke A, Krempler A, Parker AR, Jackson SP, Gennery A, Jeggo PA and Löbrich $\mathrm{M}$ (2004) A pathway of double-strand break rejoining dependent upon ATM, Artemis, and proteins locating to gamma-H2AX foci. Mol. Cell 16: 715-724.

89. Petrini JHJ and Stracker TH (2003) The cellular response to DNA double-strand breaks: defining the sensors and mediators. Trends Cell Biol. 13: 458-462.

90. Assenmacher N and Hopfner KP (2004) MRE11/RAD50/NBS1: complex activities. Chromosoma 113: 157-166.

91. Paull TT and Lee JH (2005) The Mre11/Rad50/Nbs1 complex and its role as a DNA double-strand break sensor for ATM. Cell Cycle 4: 737-740.

92. Krejci L, Chen L, Van Komen S, Sung P and Tomkinson A (2003) Mending the break: two DNA double-strand break repair machines in eukaryotes. Nucleic Acids Res. Mol. Biol. 74: 159-201.

93. Stark JM, Pierce AJ, Oh J, Pastink A and Jasin M (2004) Genetic steps of mammalian homologous repair with distinct mutagenic consequences. Mol. Cell. Biol. 24: 9305-9316.

94. Rothkamm K, Krüger I, Thompson LT and Löbrich M (2003) Pathways of DNA double-strand break repair during mammalian cell cycle. Mol. Cell. Biol. 23 5706-5715.

95. Morris SM (2002) A role for p53 in the frequency and mechanism of mutation. Mutat. Res. 511: 45-62.

96. Xia F, Amundson SA, Nickoloff JA and Liber HL (1994) Different capacities for recombination in closely related human lymphoblastoid cell lines with different mutational responses to X-irradiation. Mol. Cell. Biol. 14: 5850-5857.

97. Liang L, Shao C, Deng L, Mendonca MS, Stambrook PJ and Tischfield JA (2002) Radiation-induced genetic instability in vivo depends on p53 status. Mutat. Res. 502: 69-80.

98. Blackburn AC, McLary SC, Naeem R, Luszcz J, Stockton DW, Donehower LA, Mohammed M, Mailhes JB, Soferr T, Naber SP, Otis CN and Jerry DJ (2004) Loss of heterozygosity occurs via mitotic recombination in Trp53+/mice and associates with mammary tumor susceptibility of the BALB/c strain. Cancer Res. 64: 5140-5147. 
99. Bishop AJ, Hollander MC, Kosaras B, Sidman RL, Fornace Jr AJ and Schiest RH (2003) Atm-, p53-, Gadd45a-deficient mice show an increased frequency of homologous recombination at different stages during development. Cancer Res. 63: 5335-5343.

100. Rotter V, Schwartz D, Almon E, Goldfinger N, Kapon A, Meshorer A, Donehower LA and Levine AJ (1993) Mice with reduced levels of p53 protein exhibit the testicular giant-cell degenerative syndrome. Proc. Natl. Acad. Sci. USA 90: 9075-9079.

101. Gersten KM and Kemp CJ (1997) Normal meiotic recombination in p53deficient mice. Nature Genet. 17: 378-379.

102. Wiesmüller L, Cammenga $J$ and Deppert W (1996) In vivo assay of p53 function in homologous recombination between Simian Virus 40 chromosomes. J. Virol. 70: 737-744.

103. Willers $\mathrm{H}, \mathrm{Xia} F$ and Powell SN (2002) Recombinational DNA repair in cancer and normal cells: the challenge of functional analysis. J. Biomed. Biotechnol. 2: 86-93.

104. Akyüz N, Boehden GS, Süsse S, Rimek A, Preuss U, Scheidtmann KH and Wiesmüller $L$ (2002) DNA substrate dependence of $p 53$ mediated regulation of double-strand break repair. Mol. Cell. Biol. 22: 6306-6317.

105. Sengupta S, Linke SP and Pedeux R (2003) BLM helicase-dependent transport of $\mathrm{p} 53$ to sites of stalled DNA replication forks modulates homologous recombination. EMBO J. 22: 1210-1222.

106. Bertrand P, Rouillard D, Boulet A, Levalois C, Soussi T and Lopez BS (1997) Increase of spontaneous intrachromosomal homologous recombination in mammalian cells expressing a mutant p53 protein. Oncogene 14: 1117-1122.

107. Mekeel KL, Tang W, Kachnik LA, Luo CM, DeFrank JS and Powell SN (1997) Inactivation of $\mathrm{p53}$ results in high rates of homologous recombination. Oncogene 14: 1847-1857.

108. Saintigny Y, Rouillard D, Chaput B, Soussi T and Lopez BS (1999) Mutant p53 proteins stimulate spontaneous and radiation-induced intrachromosomal homologous recombination independently of the alteration of the transactivation activity and of the G1 checkpoint. Oncogene 18: 3553-3565.

109. Willers $\mathrm{H}$, McCarthy EE, Wu B, Wunsch $\mathrm{H}$, Tang W, Taghian DG, Xia F and Powell SN (2000) Dissociation of p53-mediated suppression of homologous recombination from G1/S cell cycle checkpoint control. Oncogene 19: 632-639.

110. Boehden GS, Akyüz N, Roemer K and Wiesmüller L (2003) p53 mutated in the transactivation domain retains regulatory functions in homology-directed double-strand break repair. Oncogene 22: 4111-4117.

111. Willers H, McCarthy EE, Hubb P, Dahm-Daphi J and Powell SN (2001) Homologous recombination in extrachromosomal plasmid substrates is not suppressed by p53. Carcinogenesis 22: 1757-1763.

112. Linke SP, Sengupta S, Khabie N, Jeffries BA, Buchhop S, Miska S, Henning W, Pedeux R, Wang XW, Hofseth LJ, Yang Q, Garfield SH, Stürzbecher HW and Harris CC (2003) P53 interacts with hRad51 and hRad54, and directly modulates homologous recombination. Cancer Res. 63: 2596-2605.

113. Saintigny $Y$, Delacote YF, Vares $G$, Petitot $F$, Lambert S, Averbeck $D$ and Lopez BS (2001) Characterization of homologous recombination induced by replication inhibition in mammalian cells. EMBO J. 20: 3861-3870.

114. Rothstein R, Michel B and Gangloff S (2000) Replication fork pausing and recombination or 'gimme a break'. Genes Dev. 14: 1-10.

115. Saintigny $Y$ and Lopez BS (2002) Homologous recombination induced by replication inhibition, is stimulated by expression of mutant p53. Oncogene 21: 488-492.

116. Janz $C$ and Wiesmüller $L$ (2002) Wildtype $p 53$ inhibits replication-associated homologous recombination. Oncogene 21: 5229-5933.

117. Paulson TG, Almasan A, Brody LL and Wahl GM (1998) Gene amplification in a p53-deficient cell line requires cell cycle progression under conditions that generate DNA breakage. Mol. Cell. Biol. 18: 3089-3100

118. Kumari A, Schultz $N$ and Helleday $T$ (2004) p53 protects from replicationassociated DNA double-strand breaks in mammalian cells. Oncogene 23 2324-2329.

119. Squires S, Coates JA, Goldberg M, Toji LH, Jackson SP, Clarke DJ and Johnson RT (2004) p53 prevents the accumulation of double-strand DNA breaks at stalled-replication forks induced by UV in human cells. Cell Cycle 3 : 1543-1557.

120. Zink D, Mayr $C$, Janz $C$ and Wiesmüller $L$ (2002) Association of $p 53$ and MSH2 with recombinative repair complexes during $S$ phase. Oncogene 21: 4788-4800.
121. Restle $A$, Janz $C$ and Wiesmüller $L$ (2005) Differences in the association of p53 phosphorylated on serine 15 and key enzymes of homologous recombination. Oncogene 24: 4380-4387.

122. Gottifredi V, Shieh $S$, Taya $Y$ and Prives $C$ (2001) p53 accumulates but is functionally impaired when DNA synthesis is blocked. Proc. Natl. Acad. Sci. USA 98: 1036-1041.

123. Stürzbecher HW, Donzelmann B, Henning W, Knippschild U and Buchhop S (1996) p53 is linked directly to homologous recombination processes via Rad51/RecA protein interaction. EMBO J. 15: 1992-2002.

124. Buchhop $S$, Gibson MK, Wang XY, Wagner $P$, Stürzbecher HW and Harris CC (1997) Interaction of p53 with the human Rad51 protein. Nucleic Acids Res. 25: 3868-3874.

125. Süsse S, Janz C, Janus F, Deppert W and Wiesmüller L (2000) Role of heteroduplex joints in the functional interactions between human Rad51 and wildtype p53. Oncogene 19: 4500-4512.

126. Zhang $\mathrm{H}$, Somasundram $\mathrm{K}$, Peng $\mathrm{Y}$, Tian $\mathrm{H}$, Zhang $\mathrm{H}, \mathrm{Bi} D$, Weber $B L$ and El-Deiry WS (1998) BRCA1 physically associates with p53 and stimulates its transcriptional activity. Oncogene 16: 1713-1721.

127. Marmorstein LY, Ouchi T and Aaronson SA (1998) The BRCA2 gene product functionally interacts with p53 and Rad51. Proc. Natl. Acad. Sci. USA 95: 13869-13874.

128. Jasin M (2002) Homologous repair of DNA damage and tumourigenesis: the BRCA connection. Oncogene 21: 8981-8993.

129. Romanova LY, Willers H, Blagosklonny MV and Powell SN (2004) The interaction of $\mathrm{p} 53$ with replication protein A mediates suppression of homologous recombination. Oncogene 23: 9025-9033.

130. Blander G, Kipnis J, Leal JFM, Yu CE, Schellenberg GD and Oren M (1999) Physical and functional interaction between p53 and Werner's syndrome protein. J. Biol. Chem. 274: 29463-29469.

131. Wang XW, Tseng A, Ellis NA, Spillare EA, Linke SP, Robles AI, Seker H, Yang Q, Hu P, Beresten S, Bemmels NA, Garfield S and Harris CC (2001) Functional interaction of p53 and BLM DNA helicase in apoptosis. J. Biol. Chem. 276: 32948-32955.

132. Yang $Q$, Zhang $R$, Wang $X W$, Spillare EA, Linke SP, Subramanian $D$, Griffith JD, Li JL, Hickson ID, Shen JC, Loeb LA, Mazur SJ, Appella E, Brosh Jr RM, Karamakar P, Bohr VA and Harris CC (2002) The processing of the Holliday junctions by BLM and WRN helicases is regulated by p53. J. Biol. Chem. 277: 31980-31987.

133. Yoon D, Wang Y, Stapleford K, Wiesmüller L and Chen J (2004) p53 inhibits strand exchange and replication fork regression promoted by human Rad51. J. Mol. Biol. 336: 639-654.

134. Yun S, Lie-A-Cheong C and Porter AC (2004) Discriminatory suppression of homologous recombination by p53. Nucleic Acids Res. 32: 6479-6489.

135. Prabhu VP, Simons AM, Iwasaki H, Gai D, Simmons DT and Chen J (2002) p53 blocks RuvAB promoted branch migration and modulates resolution of Holliday junctions by RuvC. J. Mol. Biol. 316: 1023-1032.

136. Degtyareva N, Subramanian D and Griffith JD (2001) Analysis of the binding of $p 53$ to DNAs containing mismatched and bulged bases. J. Biol. Chem. 276: 8778-8784.

137. Alani E, Lee S, Kane MF, Griffith J and Kolodner RD (1997) Saccharomyces cerevisiae MSH2, a mispaired base recognition protein, also recognizes Holliday junctions in DNA. J. Mol. Biol. 265: 289-301.

138. Elliott $B$ and Jasin M (2001) Repair of double-strand breaks by homologous recombination in mismatch repair-defective mammalian cells. Mol. Cell. Biol. 21: 2671-2682

139. Yang $Q$, Zhang R, Wang XW, Linke SP, Sengupta S, Hickson ID, Pedrazzi G, Perrera C, Stagljar I, Littman SJ, Modrich P and Harris CC (2004) The mismatch DNA repair heterodimer, hMSH2/6, regulates BLM helicase. Oncogene 23: 3749-3756.

140. Subramanian D and Griffith JD (2002) Interactions between p53, hMSH2hMSH6 and HMG I(Y) on Holliday junctions and bulged bases. Nucleic Acids Res. 30: 2427-2434.

141. Subramanian D and Griffith JD (2005) Modulation of p53 binding to Holliday junctions and 3-cytosine bulges by phosphorylation events. Biochemistry 44: 2536-2544.

142. Sommers JA, Sharma S, Doherty KM, Karmakar P, Yang Q, Kenny MK, Harris CC and Brosh Jr RM (2005) p53 modulates RPA-dependent and RPAindependent WRN helicase activity. Cancer Res 65: 1223-1233. 
143. Bachrati CZ and Hickson ID (2003) RecQ helicases: suppressors of tumourigenesis and premature aging. Biochem. J. 374: 577-606.

144. Sengupta S, Robles Al, Linke SP, Sinogeeva NI, Zhang R, Pedeux R, Ward IM, Celeste A, Nussenzweig A, Chen J, Halazonetis TD and Harris CC (2004) Functional interaction between BLM helicase and 53BP1 in a Chk1-mediated pathway during S-phase arrest. J. Cell Biol. 166: 801-813.

145. Davalos AR, Kaminker P, Hansen RK and Campisi J (2004) ATR and ATMdependent movement of BLM helicase during replication stress ensures optimal ATM activation and 53BP1 focus formation. Cell Cycle 3 : 1579-1586.

146. Yang T, Namba H, Takmura N, Nagayama Y, Fukata S, Ishikawa N, Kuma K, Ito $\mathrm{K}$ and Yamashita $\mathrm{S}$ (1997) p53 induced by ionizing radiation mediates DNA end-joining activity, but not apoptosis of thyroid cells. Oncogene 14: 1511-1519.

147. Tang W, Willers $H$ and Powell SN (1999) p53 directly enhances rejoining of DNA double-strand breaks with cohesive ends in gamma-irradiated mouse fibroblasts. Cancer Res. 59: 2562-2565.

148. Bill CA, Yu Y, Miselis NR, Little JB and Nickoloff JA (1997) A role for p53 in DNA end rejoining by human cell extracts. Mutat Res. 385: 21-29.

149. Lee H, Sun D, Larner JM and Wu FS (1999) The tumor suppressor p53 can reduce stable transfection in the presence of irradiation. J. Biomed. Sci. 6 : 285-292.

150. Okorokov AL, Warnock $L$ and Milner J (2002) Effect of wildtype, S15D and $\mathrm{R} 175 \mathrm{H}$ p53 proteins on DNA end-joining in vitro: potential mechanism of DNA double-strand break repair modulation. Carcinogenesis 23 : 549-557.

151. Dahm-Daphi J, Hubbe P, Horvath F, El-Awady RA, Bouffard KE, Powell SN and Willers $\mathrm{H}$ (2005) Nonhomologous end-joining of site-specific but not of radiation-induced DNA double-strand breaks is reduced in the presence of wildtype p53. Oncogene 24: 1663-1672.

152. Bristow RG, Hu Q, Jang A, Chung $S$, Peacock J, Benchimol $S$ and Hill $R$ (1998) Radioresistant MTp53-expressing rat embryo transformants exhibit increased DNA dsb rejoining during exposure to ionising radiation. Oncogene 16: $1789-1802$

153. Lin Y, Waldman BC and Waldman AS (2003) Suppression of high-fidelity double-strand break repair in mammalian chromosomes by pifithrin-alpha, a chemical inhibitor of p53. DNA Repair 2: 1-11.

154. Zotchev SB, Protopopova M and Selivanova G (2000) p53 C-terminal interaction with DNA ends and gaps has opposing effect on specific DNA binding by the core. Nucleic Acids Res. 28: 4005-4012

155. Vukojevic V, Yakovleva T, Terenius L, Pramanik A and Bakalkin G (2004) Denaturation of dsDNA by p53: fluorescence correlation spectroscopy study. Biochem. Biophys. Res. Commun. 316: 1150-1155.

156. Gaymes TJ, North PS, Brady N, Hickson ID, Mufti GJ and Rassool FV (2002) Increased error-prone non homologous DNA end-joining - a proposed mechanism of chromosomal instability in Bloom's syndrome. Oncogene 21: 2525-2533.

157. Boehden GS, Restle A, Marschalek R, Stocking C and Wiesmüller L (2004) Recombination at chromosomal sequences involved in leukaemogenic rearrangements is differentially regulated by $\mathrm{p} 53$. Carcinogenesis 25 : $1-9$.
158. Albor A, Kaku S and Kulesz-Martin M (1998) Wildtype and mutant forms of p53 activate human topoisomerase I: a possible mechanism for gain of function in mutants. Cancer Res. 5: 2091-2094.

159. Gobert C, Skladanowski A and Larsen AK (1999) The interaction between p53 and DNA topoisomerase I is regulated differently in cells with wildtype and mutant p53. Proc. Natl. Acad. Sci. USA 96: 10355-10360.

160. Soe K, Hartmann H, Schlott B, Stevnsner T and Grosse F (2002) The tumor suppressor protein $\mathrm{p} 53$ stimulates the formation of the human topoisomerase double cleavage complex in vitro. Oncogene 21: 6614-6623.

161. Aubrecht J, Secretan MB, Bishop AJ and Schiestl RH (1999) Involvement of p53 in X-ray induced intrachromosomal recombination in mice. Carcinogenesis 20: 2229-2236.

162. Boehden GS, Baumann C, Siehler S and Wiesmüller L (2005) Wildtype p53 stimulates homologous recombination upon sequence-specific binding to ribosomal gene cluster repeat. Oncogene 24: 4183-4192.

163. Kern SE, Kinzler KW, Bruskin A, Jarosz D, Friedman $P$, Prives $C$ and Vogelstein B (1991) Identification of p53 as a sequence-specific DNA-binding protein. Science 252: 1708-1711.

164. Brazdova M, Palecek J, Cherny DI, Billova S, Fojta M, Pecinka P, Vojtesek B, Jovin TM and Palecek E (2002) Role of tumor suppressor p53 domains in selective binding to supercoiled DNA. Nucleic Acids Res. 30: 4966-4974.

165. Donehower LA, Harvey M, Slagle BL, MacArthur MJ, Montgomery CA, Butel JS and Bradley A (1992) Mice deficient for p53 are developmentally normal but susceptible to spontaneous tumors. Nature 356: 215-221.

166. Deng C, Zhang P, Harper JW, Elledge SJ and Leder $P$ (1995) Mice lacking p21 cip1/waf1 undergo normal development, but are defective in $\mathrm{G} 1$ checkpoint control. Cell 82: 675-684.

167. Komarov PG, Komarova EA, Kondratov RV, Christov-Tselkov K, Coon JS, Chernov MV and Gudkov AV (1999) A chemical inhibitor of p53 that protects mice from the side effects of cancer therapy. Science 285: 1733-1737.

168. Schmitt CA, Fridman JS, Yang M, Baranov E, Hoffman RM and Lowe SW (2002) Dissecting p53 tumor suppressor functions in vivo. Cancer Cell 1: 289-298.

169. Ceballos E, Delgado MD, Gutierrez P, Richard C, Muller D, Eilers M, Ehinger M, Gullberg U and Leon J (2000) c-Myc antagonizes the effect of p53 on apoptosis and p21WAF1 transactivation in K562 leukemia cells. Oncogene 19: 2194-2204.

170. Soussi T, Leblanc T, Baruchel A and Schaison G (1993) Germline mutations of the p53 tumor-suppressor gene in cancer-prone families: a review. Nouv. Rev. Fr. Hematol. 35: 33-36.

171. Thompson LH and Schild D (2002) Recombinational DNA repair and human disease. Mutat. Res. 509: 49-78

172. Gebow D, Miselis N and Liber HL (2000) Homologous and nonhomologous recombination resulting in deletion: effects of p53 status, microhomology and repetitive DNA length and orientation. Mol. Cell. Biol. 20: 4028-4035.

173. Lu X, Lozano G and Donehower LA (2003) Activities of wildtype and mutant p53 in suppression of homologous recombination as measured by a retrovira vector system. Mutat. Res. 522: 69-83.

174. Meek DW (2004) The p53 response to DNA damage. DNA Repair 3 : 1049-1056 